\title{
Transcription, Epigenetics and Ameliorative Strategies in Huntington's Disease: a Genome-Wide Perspective
}

\author{
Luis M. Valor
}

Received: 17 February 2014 / Accepted: 11 April 2014 / Published online: 1 May 2014

(C) The Author(s) 2014. This article is published with open access at Springerlink.com

\begin{abstract}
Transcriptional dysregulation in Huntington's disease (HD) is an early event that shapes the brain transcriptome by both the depletion and ectopic activation of gene products that eventually affect survival and neuronal functions. Disruption in the activity of gene expression regulators, such as transcription factors, chromatin-remodeling proteins, and noncoding RNAs, accounts for the expression changes observed in multiple animal and cellular models of HD and in samples from patients. Here, I review the recent advances in the study of HD transcriptional dysregulation and its causes to finally discuss the possible implications in ameliorative strategies from a genome-wide perspective. To date, the use of genome-wide approaches, predominantly based on microarray platforms, has been successful in providing an extensive catalog of differentially regulated genes, including biomarkers aimed at monitoring the progress of the pathology. Although still incipient, the introduction of combined next-generation sequencing techniques is enhancing our comprehension of the mechanisms underlying altered transcriptional dysregulation in HD by providing the first genomic landscapes associated with epigenetics and the occupancy of transcription factors. In addition, the use of genome-wide approaches is becoming more and more necessary to evaluate the efficacy and safety of ameliorative strategies and to identify novel mechanisms of amelioration that may help in the improvement of current preclinical therapeutics. Finally, the major conclusions obtained from HD transcriptomics studies have the potential to be extrapolated to other neurodegenerative disorders.
\end{abstract}

\footnotetext{
L. M. Valor $(\bowtie)$

Instituto de Neurociencias de Alicante, Universidad Miguel

Hernández - Consejo Superior de Investigaciones Científicas, Av.

Santiago Ramón y Cajal s/n, Sant Joan d'Alacant, 03550 Alicante, Spain

e-mail:1mv@umh.es
}

Keywords Polyglutamine $\cdot$ Transcriptome $\cdot$ Epigenome Microarray $\cdot$ Next-generation sequencing $\cdot$ Amelioration

\section{Introduction}

Huntington's disease (HD) is the most common polyglutamine (polyQ) disorder, with a prevalence of 5-10 cases per 100,000 persons worldwide. In the classical variant, pathology onset occurs in mid adulthood (approximately 3040 years old) and ends with the patient's death, normally after $10-15$ years. HD is characterized by personality changes and psychiatric symptoms (e.g., affective disorders, suicide tendency, mania, apathy, and schizophrenia-like symptoms), cognitive deficits (e.g., poor planning and judgment, attention problems, and motor skill learning deficits), motor impairment (e.g., chorea, gait abnormalities, bradykinesia, and rigidity), sleep disturbance, and weight loss [1]. The basal ganglia and, in particular, the striatum, wherein the GABAergic medium spiny neurons (MSN) are especially sensitive, generally show an early marked degeneration that extends to other brain areas in later stages of the disease [1].

Conversely to more common neurodegenerative disorders, such as Alzheimer's (AD) and Parkinson's (PD) diseases, the cause of HD for all the patients is known: an aberrant expansion of the polymorphic trinucleotide sequence CAG (in the range of 37-121 repeats) at the N-terminus of the huntingtin (Htt) protein. Whereas the number of repeats is strongly correlated with the age of disease onset, additional genetic variants may contribute to the differential manifestation of the cognitive and motor symptomatology among patients [2]. In any case, the mutation has two different consequences [3]: (i) a loss-of-function effect, as one allele is no longer available for the physiological roles of normal Htt such as vesicle trafficking and synaptic transmission, and (ii) a gain-of-function effect, characterized by the presence of a misfolded mutant 
$\mathrm{Htt}(\mathrm{mHtt})$ that interferes with multiple intracellular activities through aberrant interactions and accumulates in aggregates, mainly in the cell nucleus and neuropil. Overall, these combined effects alter several cellular processes, such as protein degradation, mitochondrial respiration and transcription among many others, eventually leading to neuronal malfunction and cell loss.

Initial reports during the 1980 s and 1990s demonstrated selective altered expression of highly identifiable neuronal genes, such as neurotransmitter receptors and neuropeptides, first in patients' brains and later in animal models [4-7]. The importance of transcriptional dysregulation in the pathology of HD was demonstrated by nuclear-restricted variants of $\mathrm{mHtt}$ transgenes that reproduced part of the HD symptomatology $[8,9]$. With the advent of genome-wide approaches, transcriptomics was soon adopted to extend the catalog of affected transcripts in HD and to identify the most compromised cellular processes due to the detrimental supply of key components from the nucleus. However, the transcriptome is not limited to protein-coding genes, which represent less than $5 \%$ of the genome, and new classes of noncoding RNAs are currently in the spotlight. The continuous development of transcriptomics technologies and concurrent bioinformatic tools is increasingly enlarging our global perspective of the transcriptional phenomenon. Currently, deep sequencing techniques coexist with newly improved array platforms to maximize coverage of the entire transcriptome, including noncoding genomic features and alternative isoforms, and to connect transcriptomics with other sources of genome-wide data related to DNA modification and the occupancy of DNA-binding proteins (histones and transcription factors). In this review, I discuss the role of transcriptional dysregulation in the pathology of HD and the postulated causes for this impairment, with special emphasis on the information generated by highthroughput techniques, as they have the potential to provide a nearly complete vision of the genome regulation in response to pathology and restorative strategies.

\section{Widespread Transcriptional Dysregulation in Huntington's Disease}

A long list of gene expression datasets have been generated in less than 15 years of research on multiple HD animal and cellular models and, importantly, on postmortem material from patients (Fig. 1). The preferred system for the analysis of HD transcriptomics has been microarray technology, with some studies using alternative approaches, such as differential display transcription $[10,11]$, to capture novel changing genes not represented by the arrays at the time, or systematic qPCRbased assays [12-15], to selectively interrogate specific subsets of genes with high sensitivity as in the case of microRNAs (miRNAs), prior to the use of dedicated microarrays and deep sequencing technologies [16-19]. The results obtained using the most novel RNA-seq approach are consistent with microarray-based profiles [16, 20, 21], with the added benefit that they analyze the behavior of poorly characterized gene products, such as variants of mature miRNA or isomiRs [16].

An overview of the major conclusions derived from HD transcriptomics is given below.

Transcriptional Dysregulation Is an Early and Progressive Event

Profiling studies in HD animal models usually explore a minimally symptomatic stage at the phenotypical and morphological level that, in contrast, show a substantially disrupted transcriptome that worsens during progression of the disease [17, 22-30]. Further demonstrations of the prematurity of transcriptional alterations have been provided by highly controlled in vitro preparations in which gene expression changes occur prior to cell loss, mHtt aggregation, or mitochondrial dysfunction [12, 15, 31-35]. Additionally, evidence for transcriptional alterations was provided by the laser capture microdissection (LCM) of intact neurons from early symptomatic brain samples, which yielded a transcriptional profile largely comparable to that obtained from whole homogenates [36], indicating that a significant component of the HD signature in tissues is not derived from neuronal loss.

However, transcriptional dysregulation is not too early on time [23, 33, 37, 38], and accumulation of events are seemingly needed (e.g., mHtt concentration and nuclear shuttling) to overtly affect regulatory mechanisms. In any case, the progression of gene expression and phenotype can be correlated, as demonstrated by the identification of genes associated with performance impairment in the rotarod task and in decreased exploratory and spontaneous activities [39].

Transcriptional Dysregulation Affects Relevant Genes for Brain Function

Diverse processes are usually represented in HD transcriptional profiles: downregulation is generally associated with genes involved in signaling pathways (e.g., dependent on cyclic nucleotides and trophic factors), neurotransmitter receptor and ion channel functions (e.g., dopamine, serotonin, adenosine, GABA, and glutamate receptors), neuropeptides (e.g., proenkephalin and somatostatin), synaptic transmission (anchoring and vesicle components), and calcium binding and homeostasis, whereas upregulation is generally associated with genes related with RNA metabolism, protein folding, and stress markers. Expression of transcription and chromatin remodeling factors can be altered in either direction. A more exhaustive discussion of the biological implications of 


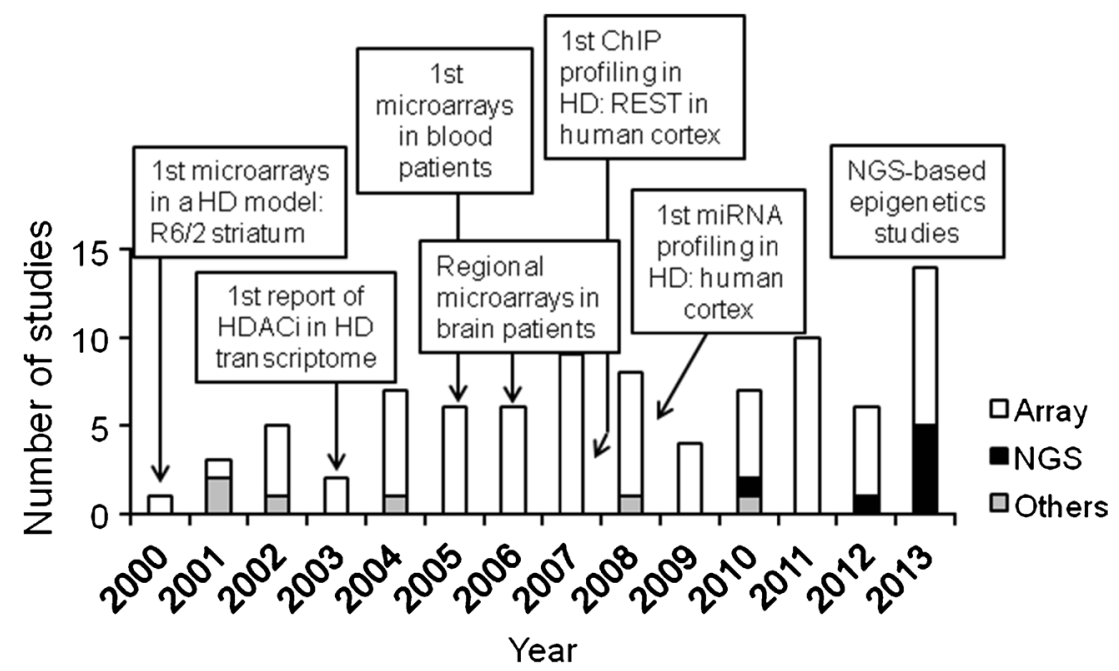

Fig. 1 Summary of the gene profiling and other genome-wide studies in HD. The graph represents the number of studies per publication year with the most relevant milestones in the field of HD transcriptional dysregulation. Note that a few studies may contain more than one approach, categorized as "Array" (expression and ChIP-on-chip), "NGS" (nextgeneration sequencing, RNA-seq, ChIP-seq, sequencing of methylated DNA) and "Others" (PCR-based: differential display, adapter-tagged competitive PCR, panels). Reports with solely reanalysis (i.e., without

deregulated genes in the context of HD can be found in the excellent reviews by Cha [40] and Seredenina and LuthiCarter [41]. Functional information can be obtained from transcriptomics studies that not only provides potential causative contributors for perturbed cellular processes but also highlights other aspects of the molecular dysfunctions that otherwise may have been overviewed. Next, some few examples are discussed to illustrate the utility of HD transcriptomics for the proposal of new research lines:

1. The relevance of intracellular signaling pathways. The first transcriptomics studies soon demonstrated impairment of signaling cascades, as in the case of cAMP/PKA-dependent signaling pathway. Thus, transcriptional dysregulation of diverse adenylyl cyclases, which promote cAMP synthesis, was concomitant to a reduction in the binding of their activator forskolin in HD mouse striata [22]. Moreover, stimulation of the cAMP pathway was beneficial for a HD cellular model [15], in which the activity of the downstream transcription factor cAMP-responsive element binding protein (CREB) was decreased. These observations have led to the study of CREB involvement in HD [42, 43] and to the use of phosphodiesterase inhibitors, which prevent degradation of cyclic nucleotides, as potential therapeutical means [44, 45]. The importance of disrupted intracellular signal transduction is further confirmed by the emergence of compensatory mechanisms to restrain the deleterious effects of altered cascades. This is the case for some $G$ protein regulators (RASD family, member $2 /$ Ras homolog generating data de novo) or chemically lesioned striatal models are not considered. References per year: 2000, [22]; 2001, [10, 15]; 2002: [12, 23, 24, 31, 65]; 2003, [173, 193]; 2004, [11]; 2005, [9, 25, 51, 135, 159, 194]; 2006, [26, 34, 36, 37, 157, 195]; 2007, [32, 38, 52, 54, 72, 110, 133, 154, 196]; 2008, [13, 27, 33, 39, 56, 103, 125, 155]; 2009, [35, 151, 152, 197]; 2010, [14, 16, 158, 165, 174, 192]; 2011, [18, 19, 30, 50, 57, 67, 119, 127, 156, 198]; 2012, [17, 66, 99, 111, 112, 181, 199]; 2013, [20, 21, $28,29,49,53,68,113,116,124,128,180,200]$

enriched in striatum (Rasd2/Rhes), RAS guanylreleasing protein $2 /$ calcium and DAG-regulated guanine nucleotide exchange factor I (Rasgrp2/CalDEG-GEF1), and regulator of $\mathrm{G}$ protein signaling $2(\operatorname{Rgs} 2))$ which actively contribute to the mHtt-induced toxicity and are downregulated at the transcript level in HD (reviewed in Seredenina and Luthi-Carter [41]). Further inhibition of this type of signaling components may constitute promising therapeutical strategies.

2. Impairment of cholesterol homeostasis. Research investigating the involvement of cholesterol in HD was boosted by a microarray study of a HD-inducible striatal cell line in which genes related to lipid metabolism and cholesterol biosynthesis were found to be downregulated [31]. Thereafter, imbalance in the levels of cholesterol and related metabolites has been found in different HD models and in patients, proportional to the length of CAG expansion. This imbalance has been documented as a decrease in brain, plasma, or cultured fibroblasts, although with some examples of cholesterol accumulation (reviewed in Valenza and Cattaneo [46] and Leoni and Caccia [47]). Brain cholesterol is primarily found as a constituent of the myelin, followed by astrocytes and neurons, and participates in myelination, neurite outgrowth promotion, formation and maintenance of the synapses, integrity of the membrane microenvironment for neuronal channels and receptors, and vesicle transport and exocytosis. Therefore, impairment of the cholesterol homeostasis may have a relevant impact in neuronal signal transduction and vesicle trafficking in HD. 
Transcriptional Dysregulation Is Not Exclusive to the Brain

HD mouse models in which the $\mathrm{mHtt}$ transgene was designed to reproduce the ubiquitous expression pattern of the endogenous Htt [48] show altered transcriptomes in the retina [26] and in nonneuronal tissues, such as blood [49] and muscle [23, $25]$, in the latter case with apparently little contributions of diabetes and weight loss. Peripheral tissues facilitate access to biomaterial and open the possibility of their use in the identification of biomarkers. Transcriptomics can determine in an unbiased manner the expression changes associated with the disease in blood samples [19, 50-52] and skin fibroblasts from patients [53]. Indeed, late and early presymptomatic stages have distinctive profiles [51], further supporting the suitability of peripheral expression changes for measuring pathology progression.

\section{HD Transcriptional Signatures Are a Complex Mixture of Common and Specific Changes}

To date, the best attempt to meta-analyze striatal profiles from different animal models (including knock-in and transgenic mice for different mHtt lengths) within the same study [38] revealed a high degree of concordance, although a definitive description of a consensus core HD signature is still lacking. Importantly, animal models are able to recapitulate relevant features of the transcriptional dysregulation associated with HD in patients [27, 36, 38, 54-57]. Common changes were also observed among different brain areas and in nonneuronal tissues $[18,23,25,28,36]$ and more strikingly among different polyQ disorders (see "Final Remarks" section), despite the apparent overrepresentation of regional and model-specific changes.

The presence of specific changes is the result of several factors as discussed below:

1. Intrinsic properties of the tissues, such as sensitivity to degeneration and tissular-specific transcription. The striatum exhibits a special sensitivity to neurodegeneration, as demonstrated by general insults that severely affect striatal cells, such as hypoxia, hypoglycemia, and ischemia [58], systemic administration of neurotoxins (e.g., 3nitropropionic acid (3-NP) and 1-methyl-4-phenyl1,2,3,6-tetrahydropyridine (MPTP)) [59, 60], and somatic CAG instability of the Htt gene [61]. This latter susceptibility is correlated with the acceleration of the pathology and can be predicted at the transcriptome level in different tissues $[62,63]$. Therefore, the striatum and, in particular, the caudate nucleus are the brain areas that show greater transcriptional dysregulation compared with cortical areas and the cerebellum, in accordance with the earliest and more severe manifestations of the disease in humans [36]. Moreover, in the striatal region, the profile may be pronouncedly distorted by a cell population shift (i.e., neuronal loss concomitant with glial activation). The effect of tissular-specific transcription is observed by the fact that striatal-enriched genes are generally more sensitive to dysregulation within the striatum [37] and also by the normal differential gene regulation across brain areas: genes with differential levels of expression tend to appear in the tissular-specific HD signature, whereas genes with similar expression levels tend to be part of nonspecific pathways that become altered in HD [30]. Whether this dichotomy is in concordance with specific and common transcriptional regulators remains to be fully determined.

2. Intrinsic properties of the models. For example, the promoter sequences driving transgene expression (e.g., ubiquitous vs neuronal-restricted) determine which cell types will be more affected, and the length of the mHtt determines the progression rate of the disease because $\mathrm{N}$ terminal transgenes lack the required signals present in full-length mHtt (either transgenic or knock-in) to promote degradation in response to misfolding [64]. Gene profiles of fast and slow progressive models were initially described as not reproducible [65] mainly because they were retrieved from dissimilar stages of the pathology; once these models were comparable, the gene profiles were significantly similar [38]. The number of CAG repeats is also relevant, as initially suggested by transgenic models $[33,66]$ and as further confirmed in heterozygous knock-in systems with descriptions of a relatively consistent and prominent transcriptional signature associated with an increasing length of repeats $[67,68]$.

3. Analytical procedures. The intrinsic properties discussed above make performing a reliable meta-analysis of distinct gene profiles difficult; this limitation is more evident if based on the results of conventional pair-wise comparisons between the control and the aberrant Htt expansion situations using arbitrary thresholds. Exploring alternative approaches has led to interesting insights that otherwise would have remained undetected: for example, the aforementioned accumulative dysregulation associated with CAG repeats, the detection of subthreshold HD signatures in a less affected brain area [30], and the dissection of the relative contribution of cell populations to the HD transcriptional signature in heterogeneous tissues [69]. In the case of biomarkers, investigation of a natural human population characterized by confounding demographic and individual factors is challenging from an analytical point of view. A first study reported 12 promising candidates from the blood of human patients [51], which were not confirmed by other studies [50, 52], even with the reanalysis of the original data [70]. However, the collection of proposed biomarkers in these studies were to some extent reproduced in independent cohorts, indicating that integrative analytical procedures are required to reach a reliable consensus. 
HD Is Not Fully Explained by Mitochondrial Dysfunction

Mitochondrial dysfunction is supported by several pieces of evidence: the mitochondrial localization of $\mathrm{mHtt}$, the defective $\mathrm{Ca}^{2+}$ homeostasis, the impairment of mitochondrial respiration and trafficking in mHtt-expressing cells, and the reduced activity of peroxisome proliferator-activated receptor gamma coactivator- $1 \alpha$ (PGC-1 $\alpha$ ), which is relevant for the expression of genes related to mitochondrial biogenesis and oxidative phosphorylation [71]. 3-Nitropropionic acid (3-NP) irreversibly inhibits succinate dehydrogenase, the enzymatic activity required for the mitochondrial electron transport chain, and induces striatal neuronal degeneration and a HD-resembling phenotype [60]; thus, 3-NP treatment is regarded as a chemicalinducible model of HD. However, striatal gene profiling demonstrated a lack of correlation between $\mathrm{mHtt}$-expressing and 3NP-treated animals [18, 55] and immortalized cell lines [72]. This is in agreement with the comparison with PGC- $1 \alpha$ knockout profile (see "PGC-1 $\alpha$ " section). Overall, energy deficiency in $\mathrm{HD}$ is not fully explained by mitochondrial dysfunction, and extramitochondrial mechanisms should be investigated.

\section{Multiple Gene Expression Regulators Are Altered in Huntington's Disease}

Among the gene expression regulators, we can find transcription factors and associated cofactors, including chromatinremodeling proteins and noncoding RNAs (ncRNA). Chromatin-remodeling proteins are gaining increasing interest in neuropathology as they are responsible for the epigenetic deficits observed in mental and neurological disorders [73, 74]. Research in HD and other polyQ disorders introduced epigenetics and epigenetic-based correctives early in the last decade, and these studies were soon extended to more common neurodegenerative disorders, such as AD. This led to the general hypothesis of epigenetic imbalance as one of the most important causes of the altered expression of genes involved in neuronal function and survival in neurodegenerative processes [75]. Since then, several modifications of histones (acetylation, methylation, ubiquitylation, and phosphorylation) and DNA (methylation and hydroxymethylation) have been described to be affected in HD (for further details, see Valor and Guiretti [76]). Regarding ncRNAs, microRNAs (miRNAs) have been extensively examined in the context of this polyQ pathology and in other neurodegenerative disorders [77]. miRNAs exert posttranscriptional inhibition by halting translation or by promoting RNA degradation [78], in the latter case consequently modulating the net transcript level of a given gene. As mentioned previously, several miRNAs are deregulated in HD, and in some cases, their potential target transcripts are found to be changed in the opposite direction $[13,14,79]$. Very recently, the involvement of a new class of ncRNAs, small CAG-repeated RNAs (sCAG-RNAs), has been described in HD. sCAG-RNAs are derived from the $\mathrm{mHtt}$ transcript and promote the degradation of messenger RNAs (mRNAs) containing CUG-rich sequences, with deleterious consequences [80], thus demonstrating that both $\mathrm{mHtt}$ protein and RNA can contribute to HD.

Mechanisms for Disruption of Gene Expression Regulators

The activity of gene expression regulators can be affected in several ways, as defined in single-gene studies:

1. By a loss of interaction with wild-type Htt. The bestknown example is the RE1-silencing transcription factor/neuron-restrictive silencer factor (REST/NRSF) that is physiologically retained by wild-type $\mathrm{Htt}$ in the cytoplasm. Thus, loss of a single allele promotes the nuclear translocation of this factor and alters the expression of neuronal genes [81], as discussed in the next section. Other examples are nuclear factor kappa B $(\mathrm{NF}-\mathrm{kB})$, which is translocated from dendrites to the nucleus through the interaction with wild-type Htt [82], and nuclear receptors [83], including liver $\mathrm{X}$ receptor (LXR), a key regulator of cholesterol metabolism [46, 47].

2. By aberrant interactions with $\mathrm{mHtt}$. This is the bestcharacterized action and was originally proposed because several transcription regulators, such as the acetyltransferase CREB-binding protein (CBP), the histone deacetylase complex subunit $\mathrm{mSin} 3 \mathrm{a}$, the tumor suppressor $\mathrm{p} 53$, the transcription elongation regulator 1 (Tcerg1/ CA150), and the TATA-binding protein (TBP), among many others [84-88], were found within the mHtt aggregates, suggesting a depletion of regulatory factors needed to maintain normal levels of expression. Other evidences further support mHtt-dependent transcription failure. For example, the expression of exogenous $\mathrm{mHtt}$ produces cell-autonomous transcriptional dysregulation, as documented by transcriptomics studies [12, 15, 33, 34], and alters in vitro reporter expression [15, 84, 89-91]. Additionally, there is a CAG repeat-dependent transcriptional response in the context of both loss- and gain-of-function, as previously mentioned. However, the pathogenic role of $\mathrm{mHtt}$ aggregates is still under debate, and recent evidence favors soluble $\mathrm{mHtt}$ as the toxic form responsible for the molecular failures observed in the pathology [92-95]. Regarding transcription, aggregative inclusions of $\mathrm{mHtt}$ did not significantly decrease or change the nuclear distribution of some transcriptional regulators [90, 96, 97], and soluble forms of $\mathrm{mHtt}$ were able to inhibit their activities per se [98-101], as occurs in the case of the housekeeping specificity protein 1 (Sp1), CBP, and TBP. In agreement with these observations, altered gene 
expression can appear prior to nuclear Htt aggregation as already discussed [31, 100, 102]. Finally, interference by $\mathrm{mHtt}$ can also occur at the promoter level through direct association with DNA [103, 104].

3. By the disruption of upstream gene expression regulators. Apart from miRNAs, transcription factors and associated cofactors can also be prominently deregulated at the transcript level, as retrieved by functional enrichment analyses of pathological gene profiles. Nonetheless, such dysregulation does not always contribute to the progression of the disease by affecting downstream target genes, but it can also be a part of the homeostatic response in an attempt to restore lost activities. An example is the CCAAT-binding protein nuclear factor Y (NF-Y) that is present in mHtt aggregates with a concomitant reduction in protein levels but upregulated at the mRNA level [105].

4. By abnormal protein degradation, by either promoting or preventing the removal of regulators such as CBP [76] or the Wnt-dependent transcriptional coactivator $\beta$-catenin [106], respectively.

Genome-Wide Approaches to Link Transcriptional Dysregulation and Altered Regulator Activities

To gain further insight on the regulatory mechanisms responsible for HD signatures, gene expression datasets can be analyzed for the enrichment of transcription factor binding sites (TFBS) to infer the most promising factors involved in the transcriptional deficits. Along the same lines, the 3'UTRs of deregulated genes can be scanned for the putative binding of miRNAs. Early attempts, although limited by the scarce knowledge of genomic sequences at the time, were able to identify a small subset of deregulated genes with DNA motifs at their promoters for Sp1 [23] and CREB [15], the latter being implicated in neurodegenerative disorders [107]. Some recent reports have predicted the enrichment of more representative binding motifs in large datasets, such as the sequences for NF-kB, Sp1, p53, REST, the procaspase activator HIP1 protein interactor (HIPPI), or miR-22 [14, 16, 20, 21, 28, 72, 108, 109], to cite some examples.

There are, however, obvious limitations to the prediction strategy. First, regulatory proteins are able to bind through noncanonical consensus sequences or indirectly through the recruitment of other associated factors; second, the use of predicted DNA motifs may depend on the tissue-specific context, i.e., on the presence of specific cofactors and interacting partners; and third, this strategy is not valid for chromatin-remodeling proteins, as they do not recognize any primary sequence in the DNA. Finally, predictions are highly dependent on the assumptions made by the algorithms, which can be especially problematic in the case of miRNA-binding sequences. Two different approaches circumvent these issues: (i) meta-analysis of gene profiles to determine the degree of similarity between the HD signature and the transcriptional changes caused by genetic manipulation of particular regulators $[66,104]$ and (ii) mapping the genomic occupancy of nuclear proteins. This second approach offers an important advantage over the former one: both direct and indirect targets are distinguishable, without the confounding homeostatic response that may be highly specific for a particular genetically engineered model. In the HD field, initial efforts exploited array platforms to examine the DNA positions originally bound to the protein of interest after immunoprecipitation with a specific antibody in the so-called ChIP-on-chip approach $[103,110,111]$. As occurs with transcriptomics-based techniques, this approach was not fully unbiased but restricted to the probes spotted in the arrays, and usually the promoter regions of known genes were interrogated without considering the regulatory regions distal to the transcription start site (TSS), thus excluding enhancers and the promoters of undiscovered genes and alternative isoforms from the analysis. Currently, next-generation sequencing is the preferred approach to investigate genomic occupancy (ChIP-seq) [20, $21,28,66,112,113]$, as it enables nearly nucleosome resolution, allows the redefinition of the consensus DNA motif and possible variants, and explores the contribution of neighboring sequences.

Next, studies designed to link transcriptomics with the activity of particular expression regulators are discussed in detail.

\section{REST}

REST is a Kruppel-type zinc finger protein that was originally described as a repressor of neuronal genes in nonneuronal cells for maintaining the phenotypic identity of these cells, according to its high expression level in embryonic and nonneuronal cells, opposed to the lower level observed in neurons (reviewed in Adachi and Monteggia [114]). As previously commented, this repressor can enter the nucleus of HD neurons and repress the expression of cortical transcripts, such as brain-derived neurotrophic factor (BDNF) [81]. To identify additional HD genes that are dysregulated because of REST binding, chromatin lysates from patients with advanced grade of disease were examined by a ChIP-on-chip approach using an array specifically designed to explore canonical RE1/ NRSE sites in the human genome [110]. To minimize the use of human material, it is possible to take advantage of the high functionality of REST in proliferative cells and employ ChIPseq information derived from accessible cell lines to enlarge the list of candidate genes for further examination in HD signatures. In doing so, it was possible to identify the first long noncoding RNAs (expressed in the locus of human accelerated region 1 (HAR1)) as downregulated in the striatum of HD patients [115] and to tightly associate direct REST 
regulation with the decreased expression of miRNAs and neuronal genes in a HD cell model [116].

\section{Forkhead Box Protein 1 (Foxp1)}

Foxp1 and other members of the subfamily play important roles in cell-type-specific gene expression in the heart, lung, thymus, immune cells, and developing brain. Haploinsufficiency in humans may be the cause of an intellectual disability that severely affects the onset of speech and language and is also commonly associated with distinctive facial features, autistic traits, and congenital malformations [117]. Foxp1 shows high levels of expression in the striatum and is downregulated in HD models and in the caudate nucleus from patients [37]. Genome-wide analysis of the involvement of Foxp1 in HD transcriptional dysregulation has been conducted in a series of concatenated experiments. First, combined microarray and ChIP-seq analysis in a striatal cell line overexpressing this transcription factor identified a set of bona fide target genes, including some associated with inflammatory and immunological disorders in other systems [66]. In agreement with the in vitro results, viral transduction of Foxp 1 primarily led to the repression of immune-related genes in the adult striatum. This pattern moderately anticorrelated with published HD transcriptional signatures of animal models and patients [66]. Although this study suggested an interaction with $\mathrm{mHtt}$, it is not clear whether the Foxp1 actions in glial cells are direct, because the main transduced cells in the in vivo experiments were neurons, and endogenous Foxp1 binding has not been examined in a symptomatic scenario. In any case, modulation of Foxp1 activity offers a potential new strategy to ameliorate the polyQ pathology by restricting astrocytic and microglial activation in HD.

\section{Heat Shock Factor 1 (HSF1)}

HSF1 is a leucine zipper transcription factor and a key regulator of the heat shock proteins (HSPs), including chaperones involved in protein homeostasis (folding, degradation, targeting, etc.), the expression of which is induced in response to different types of stress. In fact, some reports demonstrated an altered gene expression pattern for some of these proteins $[32,105,118]$, and ameliorative strategies aimed at enhancing either HSP or HSF1 activities have been proposed to be beneficial in HD (see "Transcriptomics-Based Ameliorative Strategies" section). To understand the potential role of HSF1 in HD, a ChIP-seq analysis was conducted in the $\mathrm{mHtt}-$ expressing immortalized striatal cell line STHdhQ111/Q111 [112]. In the basal state, relatively few loci were bound by HSF 1 in this cell line, and the majority of these loci $(\sim 75 \%)$ were the same as in the control STHdhQ7/Q7 cells. However, under heat shock conditions, HSF1 showed increased genomic binding in the control cell line that was impaired under the expression of the expanded polyQ version and affected more than one third of HSF1-dependent genes. Whereas proteostatic genes were enriched in the HSF1-associated signature in the two cell lines, genes showing deficits in both gene expression and HSF1 binding in the mutant condition were represented by other unrelated functions, suggesting that the response to HSF1-induced stress is largely preserved in this HD model. However, this situation is more complex in vivo [119], as we will see in brief. In any case, a significant number of HSF1 targets were found in the HD signature of animal models and patients, pinpointing the potential relevance of HSF1-dependent transcription in the pathology [112].

$P G C-1 \alpha$

PGC- $1 \alpha$ is a transcriptional coactivator that regulates the expression of mitochondrial genes among other targets. Its potential relevance in HD has been suggested by a specific decrease in PGC-1 $\alpha$ in the postmortem caudate nucleus of HD patients, a similar motor phenotype in PGC- $1 \alpha$ knockout and HD mice that is worsened when combining both mutations and by the fact that overexpression experiments restoring PGC- $1 \alpha$ levels ameliorated neurodegeneration and $\mathrm{mHtt}$ aggregation $[104,120]$. In the seminal study by Krainc and coworkers [104], microarray analysis of knockout mice revealed deregulated genes involved in oxidative phosphorylation, mitochondrial function, and the electron transport chain. These pathways were also altered in HD patient profiles [36]. However, a deeper comparison with HD datasets did not show a significant transcriptome-wide overlap $[55,120]$, indicating that disruptions of mitochondrial pathways are not sufficient to elicit the widespread transcriptional response reported in $\mathrm{HD}$, in agreement with the observation made with chemically induced mitochondrial dysfunction (see "HD Is Not Fully Explained by Mitochondrial Dysfunction" section).

\section{Epigenetic Marks and Associated Proteins}

Epigenetic marks that are linked to physiological processes, such as memory formation, and to intellectual disabilities and aging [121-123] have been investigated in a genome-wide manner in HD. These marks include those that are associated with active genes (H3K9/14 ac and H4K12ac in the promoters and adjacent regions of the R6/2 striatum [111] and in the nonrepetitive genome of the N171-82Q hippocampus [28] and H3K4me3 in the R6/2 cortex and striatum [21]) and with repressed genes (H3K9me3 [113] and DNA methylation [20] in STHdhQ111/Q111 and control STHdhQ7/Q7 cells). However, in the latter case, 5-methylcytosine $(5-\mathrm{mC})$ and 5hydroxymethylcytosine $(5-\mathrm{hmC})$ were in principle not distinguishable. 5 -mhC is highly enriched in neurons and may constitute an intermediate step in demethylation, leading to 
gene derepression [76]. The genomic pattern of this modification has been determined and shows a general reduction in the presymptomatic cortex and striatum of YAC128 mice [124]. Interestingly, changes in the local levels of 5-hmC correspond to changes in expression in the same direction for selected genes, suggesting a positive association with gene activation that is altered in HD.

Surprisingly, the genome-wide correlation between differential histone acetylation and gene expression is poor, despite observance of a net hypoacetylation $[28,111]$. Methylation of either histones or DNA appears to be more correlated [20, 21, 113], most likely reflecting a distinct biological relevance for epigenetic marks in HD. Alternatively, it is tentative to speculate that the use of the same deep sequencing-based technology to map either gene expression or epigenetic marks may allow better data integration for comparative purposes. Even in these studies, the correlation is not globally consistent, as it is possible to find a high proportion of genes with no correlation or with a correlation opposite to expectations. At least three possibilities may explain these discrepancies: (i) additional regulatory mechanisms are required to totally connect transcriptional and epigenetic dysregulation (see "Toward an Integrative Model of HD Transcriptional Dysregulation" section), (ii) homeostatic responses may emerge in a locus-specific basis to eventually restore expression by alternative means, and (iii) epigenetic modifications may have differential roles or repercussions in transcript regulation depending on the genomic location. In this sense, a general theme emerges that the altered epigenetics at TSS and the surrounding regions are more prone to be correlated with altered expression in HD, thus affecting genes with primary roles in synaptic transmission, cytoskeletondependent processes, and signal transduction [20, 21, 28, 113]. In addition, broad islands of $\mathrm{H} 3 \mathrm{~K} 4$ methylation around TSS in control animals are better predictors than the sharp islands of downregulation observed in transgenic mice [21], indicating that the shape of the binding profile somehow reflects specialized functions in gene regulation.

To complement these results, a genome-wide landscape of chromatin-remodeling proteins is missing. At the moment, a reduction of the hypomethylation of the H3K4 mark in HD has been ascribed to the upregulation of the specific histone demethylase lysine (K)-specific demethylase 5C (KDM5C/ $\mathrm{SMCX} / \mathrm{Jarid} 1 \mathrm{c})$. This is supported by knockdown experiments that reported an increase in the expression levels of selected genes [21].

In the absence of nucleosome resolution, meta-analysis of transcriptome data from different studies may provide key insight. Histone deacetylation as a result of decreased acetyltransferase and increased deacetylase activities is present in several polyQ models, although this latter finding needs further clarification [76]. Anyway, general nonspecific deacetylase inhibition leads to phenotypical amelioration (see "Transcriptomics-Based Ameliorative Strategies" section). Therefore, identifying the relevant histone deacetylases (HDACs) in these beneficial effects may help in the development of more specific drugs. Studies in yeast revealed a significant overlap between $\mathrm{mHtt}$-induced downregulation [125] and the target genes identified to bind Rpd3 (the ortholog of HDAC3) in a separate ChIP genomic mapping [126]. Interestingly, the yeast mutant for a component of the Rpd3 complex, Ume1, suppresses $\mathrm{mHtt}$ induced toxicity [127]. In mice, the involvement of HDACs is more complicated, as the knockdown of several isoforms in a mHtt-expressing context did not have apparent beneficial effects [76]. The exception is HDAC4, the reduction of which improved a series of faulty phenotypical, electrophysiological, and biochemical properties without restoring the HDassociated transcriptome [128]. However, marginal changes such as the rescue of BDNF levels were observed. A parallel study of HDAC4 knockout postnatal brain casts doubt on the gene-repressive role of this protein, in contrast to the conclusions obtained in the overexpression approach [129], because the pattern of acetylation was not altered, and only minor changes were observed at the level of the transcriptome [130]. A strong functional redundancy by other family members is an alternative plausible explanation for these negative results.

\section{Huntingtin}

Interestingly, $\mathrm{Htt}$ can bind directly to DNA, as shown in immortalized striatal cell lines and in brain tissue from R6/2 mice and patients, not only at the promoter level but also to intronic and intergenic regions, including repetitive sequences [103]. Because the cell lines were derived from homozygous knock-in strains bearing different polyQ extensions, it was feasible to compare the behavior of two different Htt versions (bearing the normal and a pathological length of polyQ) at the DNA binding level. Strikingly, they exhibited a distinct pattern of genomic occupancy at the promoter level in a ChIP-onchip approach, with no correlation between Htt occupancy and gene expression changes. Variants of recombinant Httexon 1 were able to bind in vitro to multiple known DNA motifs in a polyQ-dependent manner and change the conformation of the DNA [103], suggesting that the effects of $\mathrm{Htt}$ binding may involve a generic and most likely nonspecific mechanism of interference and alteration of chromatin structure. The function of wild-type $\mathrm{Htt}$ in the nucleus deserves further investigation, despite its low abundance in this compartment, as an early report suggested a scaffolding role for multiprotein complexes in nuclear processes [131].

Toward an Integrative Model of HD Transcriptional Dysregulation

A review of the vast literature together with a systematic analysis of transcription factor activities as performed by Cha and colleagues [103] leads to the conclusion that dozens 
of gene expression regulators are affected in HD. Although the precise contribution of each regulator to the HD signature remains to be determined with temporal and regional precision, it is reasonable to conclude that a few factors cannot be responsible for the complex gene profiles observed in the transcriptomics studies. Causal relationships are difficult to tract, and homeostatic responses are intermixed with deleterious dysregulation [41]. Moreover, our still limited understanding of basic regulatory processes, such as those represented by epigenetic mechanisms in neuronal gene expression, enhances our handicap in determining the precise origin of HD transcriptional dysregulation ([76], Lopez-Atalaya and Barco, in preparation).

Integrating different regulatory mechanisms may provide a more complete picture, as changes in expression levels may be the result of disruption of convergent regulators (Fig. 2). Transcription factors may shape epigenetics through the control of chromatin-remodeling protein expression, as in the case of histone methylation. The reported global hypermethylation of H3K9 in HD mouse models and in patients [132-135] has been explained as a result of abnormal increase of binding activity to the promoters of chromatin regulator genes: (i) the binding of $\mathrm{Sp} 1$ and $\mathrm{Sp} 3$ to the promoter of the histone-lysine N-methyltransferase SET (SU(VAR)3-9, enhancer of Zeste, Trithorax) domain bifurcated 1 (SETDB1, also known as ESET) [134] and (ii) the binding of caudal type homeobox 2 (Cdx2) to the promoter of the DNA-dependent ATPase/ helicase alpha thalassemia/mental retardation X-linked (ATRX) [136]. Interestingly, it has been proposed that CBP is an indirect repressor of SETDB1 [137], which reduction in HD may also contribute to SETB1 upregulation. In another example, REST appears to be a primary cause of miRNA dysregulation in HD [138] that can also influence epigenetics. In combination with the corepressors $\operatorname{Sin} 3 \mathrm{a} / \mathrm{b}$ and CoREST, REST recruits multiple chromatin-remodeling complexes containing histone methylases (G9a) and demethylases (LSD1 and KDM5C), histone deacetylases (HDAC1 and HDAC2), and the methyl-CpG-binding protein $\mathrm{MeCP}$ 2, among others. REST binding moderately correlates with decreased histone posttranslational modifications associated with active genes and increased histone methylation associated with repression [138]. To be more precise, a decoy oligodeoxynucleotide containing REST motifs was able to remove REST from the promoters of downregulated genes in $\mathrm{mHtt}$-expressing striatal cell lines, with an increase in K9H3ac levels and a reversal of expression deficits [139]. Finally, miR-9/miR-9* closes the circle by providing a feedback mechanism for its own REST-dependent transcriptional decrease in HD as it regulates REST and CoREST expression [13]. Although causality has not yet been well established, the relationship between transcription factors and epigenetics has been assessed at the genomic scale. In particular, altered patterns of DNA methylation have been linked to the binding of the transcription factor Fos-related antigen 2 (Fra-2), the proto-oncogene JunD, and sex-determining region Y-box 2 (Sox2) [20]. Bisulfite sequencing of the DNA from the $\mathrm{STHdhQ} 111 / \mathrm{Q} 111$ and STHdhQ7/7 cell lines identified differential patterns of cytosine methylation that were more evident at CpG-poor regions. The primary focus was on low methylated CpG-poor regions, as they could be potentially created by transcription factor binding, as reported in embryonic stem cells [140]. While seeking candidates, Sox2 and the
Fig. 2 Convergent disruption of regulatory mechanisms for differentially expressed genes in HD. Schematic representation of a hypothetical deregulated gene in HD, which transcriptional dysregulation may be the result of correlated changes in the complex genomic redistribution and occupancy of transcription factors, epigenetic marks, and miRNAs. SNPs, although invariant, may contribute to the susceptibility to the expression change. Arrow, direction of the gene; shade box, $\mathrm{CpG}$ island

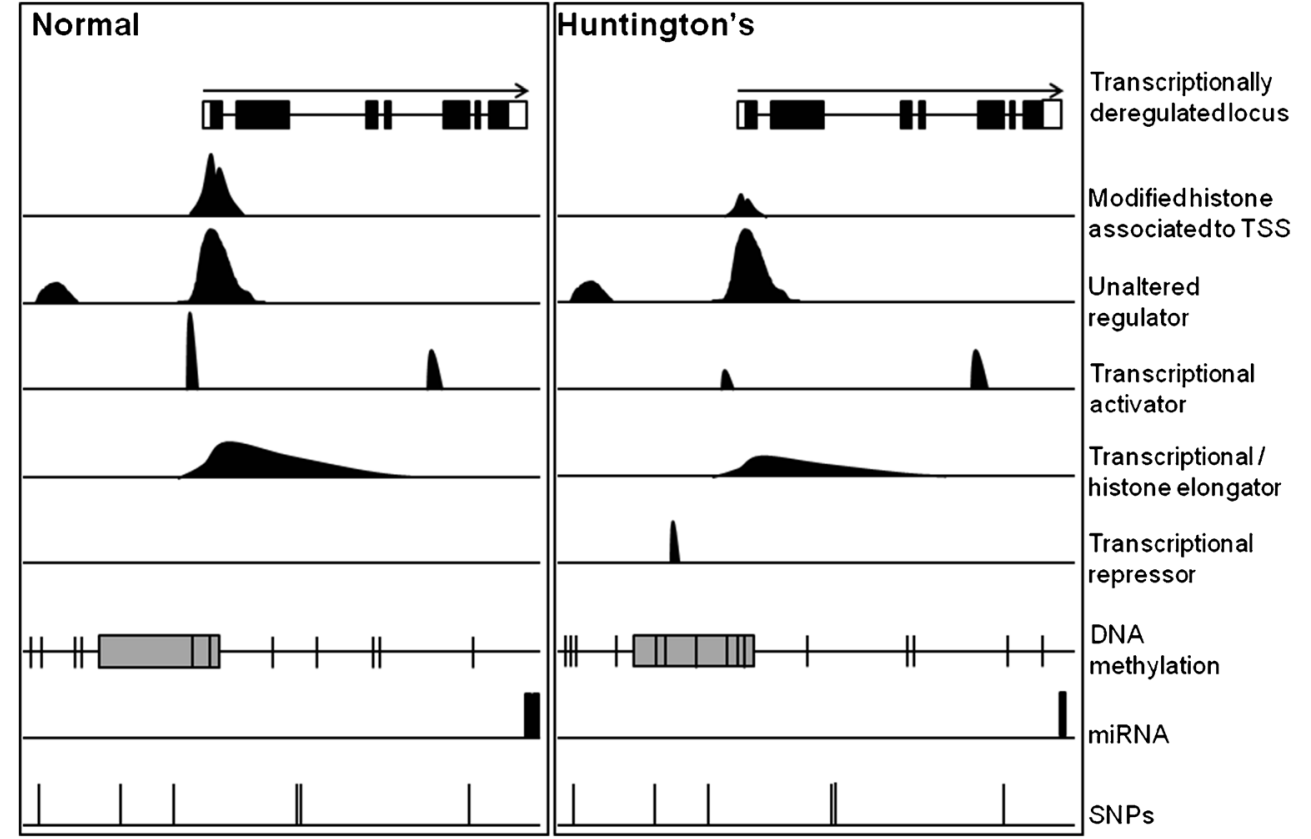


AP-1 members Fra-2 and JunD were further investigated, as they were deregulated at the transcriptional level, and their binding motifs were enriched in these regions. Confirming expectations, ChIP-seq experiments showed a complete loss of Sox 2 in mHtt-expressing cells and a negative correlation between changes in the binding of AP-1 factors and DNA methylation, primarily in distal positions [20].

Another aspect to consider for integration is the fact that histones and transcription factors can be posttranslationally modified by the same enzymes. For example, mitogen- and stress-activated kinase 1 (MSK-1) phosphorylates both histone H3 and CREB [141], and CBP acetylates not only histone tails but also transcription factors relevant to HD, such as $\mathrm{p} 53$. The tumor suppressor factor p53 interacts with $\mathrm{mHtt}$ [84] and can mediate the cytotoxicity and mitochondrial dysfunction initiated by $\mathrm{mHtt}$ [142]. More recently, p53 was found to be hyperacetylated in HD models, in accordance with a proapoptotic role [143], although $\mathrm{mHtt}$ expression could also induce hypoacetylation at the same residue [144]. These apparently paradoxical results can be explained by the complex pattern of p53 acetylation [145] because different combinations of lysines become acetylated in response to apoptosis and DNA damage or to the neuroprotective effect triggered by pharmacological treatment [146]. Another example of CBP-target protein is the RNA polymerase I factor upstream binding factor 1 (UBF1), found to be depleted in both animal and cellular HD models together with downstream ribosomal precursor mRNA [147]. Overall, due to its multiple interactions, CBP may act as a scaffolding and acetylation source for several nuclear proteins within the same locus.

\section{Transcriptomics-Based Ameliorative Strategies}

In addition to elucidating the cause and consequences of transcriptional dysregulation in HD, transcriptomics analysis has been used to test the efficacy of ameliorative strategies that directly or indirectly restore the altered activity of gene expression regulators. In this section, the genome-wide studies aimed at analyzing the transcriptional changes associated with amelioration by genetic and pharmacological means are summarized.

Gene Profiling Analysis for the Design of Ameliorative Strategies

Transcriptional profiles can be considered to be intermediate outcomes between the origin of the pathology (e.g., mutation of the Htt gene in HD) and the phenotypical manifestation at the level of behavior. Brain transcriptomes have the potential to record experiences, plasticity events, perturbation episodes, and medical interventions either in a transient or, as often occurs with neuropathologies, in a permanent manner. In the case of $\mathrm{HD}$, the accumulation of gene expression rearrangements involves direct regulatory mechanisms, cytosolic processes that affect the fine-tuned activation of downstream signaling pathways converging in the nucleus, and the transcriptional homeostatic responses to minimize damage, which together constitute the "disease signature." In the same way, it is possible to define the "ameliorative signature" as the fraction of genes which expression is restored by a particular treatment $[148,149]$. This signature is also useful in the search for biomarkers for monitoring progression deceleration. In theory, the analysis of HD transcriptomics can (i) provide a quantifiable output of the suitability of preclinical therapeutics, (ii) propose novel strategies based on meta-analyses of concurrent genome-wide data, and (iii) identify the players involved in amelioration, to finally obtain invaluable insights for the improvement and design of ameliorative strategies.

\section{Evaluation of mHtt Targeting}

Long-term silencing of mHtt by RNA interference (based on either small hairpin RNA or artificial miRNAs) represents a promising strategy to alleviate the gain-of-function effects in patients [150]. To reach an optimal balance between efficacy and safety, the effect of nonallele-specific interfering RNAs has been studied. In two different designs [151, 152], nonspecific targeting of $\mathrm{Htt}$ proved to be beneficial in vivo despite knocking down the endogenous wild-type variant; tolerance to wild-type Htt silencing is not exclusive to rodents and has also been described in adult rhesus macaques [153]. Of note, there were transcriptional changes caused by the delivery of these interfering RNAs in the control striatum. This transcriptomic effect, associated with wild-type Htt reduction, was partially consistent with diverse knockdown scenarios in HD models [36, 38, 154, 155], thus confirming the loss-offunction signature in HD. A third study minimized the toxic side effects of off-targeting silencing (unintended silencing of unrelated genes) by focusing the design of interference RNAs on the seed sequence that recognizes the Htt transcript. A screening complemented with microarray analysis in transiently transfected HEK293 cells identified two small RNA candidates that met the criteria of minimal off-targeting (very low number of altered transcripts) and high efficacy (large reduction in the Htt transcript). Subsequent long-term assessments demonstrated a lack of overt neurotoxicity in vivo [156].

\section{Modulators of polyQ-Induced Toxicity}

One of the main advantages of proliferative cellular-based models is the ability to conduct large systematic and unbiased screenings. Regarding $\mathrm{mHtt}$-expressing cells, this approach allows the identification of both tractable intracellular pathways and novel compounds by investigating the reversal of 
polyQ-induced cell death. This information would be useful for the posterior design of therapeutics in animal models. Target candidates for amelioration can be determined within the HD signature. Thus, overexpression may potentially restore cellular deficits (e.g., glucose metabolism and oxidative stress) [12] and potentiate the so-called homeostatic response; for example, a significant proportion of the upregulated genes in stably transfected cell lines were able to promote the clearance of $\mathrm{mHtt}$ and slow its accumulation in subsequent overexpression experiments [157]. Alternatively, the screening of a library of compounds allows for the proposal of mechanisms of death prevention by using transcriptomics information as an unbiased starting point. This is the case of the microtubule destabilizer podophyllotoxin, which enhances survival through the activation of the ERK pathway via the microtubule-associated Rho/Rac activator, guanine nucleotide exchange factor H1 (ARHGEF2/GEF-H1) [158].

\section{Combined Pharmacological Treatments}

Cocktail preparations may have synergic actions in improving cognitive and motor symptoms. This is the basis for the triple treatment used in the fast progressive R6/2 transgenic model. This treatment aims to increase neurotransmitter levels and mitigate mitochondrial dysfunction simultaneously, using the acetylcholine esterase inhibitor tacrine, the monoamine oxidase A inhibitor moclobemide, and creatine [159]. Interestingly, this combined treatment alleviates the HD phenotype more successfully than single-drug administration and globally reverses transcriptional changes: nearly $50 \%$ of the profile returned to normal levels.

\section{Environmental Enrichment}

Several reports indicated that the housing conditions of HD mice have an impact on disease progression and opened the possibility for occupational-related therapies. Thus, animals maintained under environmental enrichment (i.e., with opportunities for frequent exploration, interaction with novel objects, climbing, and other voluntary exercise in a changing environment) exhibited phenotypical amelioration and an extended survival rate [160-163]. Although long-term environmental enrichment is known to rescue deficits in genes, such as BDNF, the cannabinoid receptor 1, and the striatal marker dopamine and cAMP-regulated neuronal phosphoprotein (DARPP-32/Ppp1r1b)) [164], a global transcriptomic analysis failed to fully associate the effects of enrichment with any change in gene expression and concluded that the beneficial effects were due to a reduction in aggregate load [165]. In contrast, the environmental enrichment paradigm was reported to cause significant transcriptional rearrangement in other studies [166-168], probably indicating the need for standard procedures.
Restoration of BDNF Levels

The meta-analysis of datasets from diverse sources, as discussed in the "Genome-Wide Approaches to Link Transcriptional Dysregulation and Altered Regulator Activities" section, can be extended to other gene products not directly related to expression regulation. In cases where the overlap is significant, it may be feasible to investigate the ability of available drugs to modulate newly identified targets or their associated pathways. This principle is well represented by the prosurvival factor BDNF. Depletion of wild-type Htt not only leads to the transcriptional repression of the $B d n f$ locus but also interferes with the trafficking of BDNF-containing vesicles. Overall, cortical supply of this neurotrophic factor to the striatum becomes impaired in HD [169]. Cross-comparison between HD and BDNF knockout datasets from the striatum revealed their high similarity, indicating the importance of BDNF deficits in this pathology. However, the concordance of BDNF-deficient profiles was higher in HD caudate patients compared with the transgenic R6/2 model, in agreement with a primary loss-of-function mechanism to alter BDNF levels. In any case, the ameliorative potential of BDNF-based therapies was demonstrated in HD animal models [170, 171], although a corresponding reversal of the HD transcriptome remains to be tested.

\section{Targeting Expression Regulators}

Because transcriptional dysregulation is an early event in HD, directly targeting expression regulators may have an influence on the disruption of other processes in the neuron. This idea is supported by numerous experiments that rescued altered transcriptional activities by either overexpressing activators or knocking down repressors, thus restoring the expression levels of selected target genes and improving the well-being of sick animals and unhealthy cells. Interestingly, augmentation of the expression levels of wild-type Htt at the transcriptional regulatory level has been proposed to restore its physiological roles, as exemplified by homeodomain transcription factor Engrailed, which prevents $\mathrm{mHtt}$ aggregation and neurodegeneration by activation of endogenous $\mathrm{Htt}$ in a Drosophila model of HD [172]. The next section summarizes ameliorative strategies that have been tested in HD cellular and animal models to correct aberrant nuclear activities and have been monitored by gene expression profiling.

\section{HDAC Inhibitors (HDACi)}

The drugs belonging to different chemical families that are capable of inhibiting deacetylase activity are generally referred to as HDACi. Therefore, these drugs counterbalance possible deficits in acetyltransferase activity and restore the acetylation levels of histones and other nuclear proteins. This 
is the main proposed mechanism underlying the transcriptional-dependent amelioration of pathophenotypical traits observed in HD models (see Valor and Guiretti [76] for further details). In an attempt to identify the target genes responsible for such amelioration in HD, Ferrante and coworkers conducted a series of microarray studies in mouse models chronically treated with butyrate compounds. The correction of the HD signature was extremely limited [135, 173]; however this correction can involve a few highly relevant candidates for the mouse, including proapoptotic caspase-9 [135]. Alternatively, HDACi can exert their effects through the indirect activation of compensatory mechanisms. This is the case of the inhibition of the cytosolic sirtuin 2 (Sirt2), which failed to globally correct transcriptional dysregulation but reduced the shuttling of sterol regulatory element binding protein 2 (SREBP-2) to the nucleus, promoting downregulation of sterol biosynthesis genes independently of the $\mathrm{mHtt}$ expression. Thus, Sirt2 inhibition conferred neuroprotection by modulating cholesterol homeostasis [174]. In terms of HD signature reversal, the use of HDACi $4 b$ was more successful. This treatment definitively normalized the expression of one third of deregulated genes, with a total trend toward normalization of more than $80 \%$ of altered genes in the cortex, striatum, and cerebellum in transgenic R6/2 mice [56]. Importantly, HDACi treatment may have an impact, although subtle, on peripheral biomarkers [50, 51] that can be monitored for amelioration during treatments. It is worth noting that the acetylated status of hundreds of proteins can be influenced by HDAC inhibition [175]. Therefore ameliorative strategies based on the use of HDACis are beneficial due to their combined effects on histone and nonhistone substrates, either nuclear or cytosolic.

\section{Anthracyclines}

These drugs with antibiotic and anticancer properties have different mechanisms of action that involve interaction with the DNA, including histone eviction [176]. In the case of the two anthracyclines tested in pharmacological therapy of HD, mithramycin and chromomycin, binding to the minor groove of DNA promotes the displacement of GC-rich binding regulators, such as the Sp1 family members, with important consequences on restoring the imbalance between histone methylation and acetylation [76]. Biochemical and phenotypical amelioration was accompanied by the correction of a relatively small number of genes, including DARPP-32 and calcium/ calmodulin-dependent protein kinase Camk1g, as determined by microarray analysis [133].

\section{Activators of Heat Shock Proteins (HSPs)}

Due to the protective actions of HSPs in the management of misfolded and aggregated proteins, it is not surprising that ameliorative strategies aimed at enhancing HSP activity reduced polyQ-induced toxicity in parallel with intracellular mHtt aggregate load. This enhancement can be achieved by using chemical inhibitors of the ATP binding of HSP90, including the antibiotic geldanamycin and its derivatives, 17-AAG and 17-DMAG, thus affecting the repressive actions on HSF1 expression, the master regulator of HSPs [177]. Bates and colleagues explored the beneficial effects of the HSP90 inhibitor NVP-HSP990 in the R6/2 model [119]. This study is an interesting example of dissecting the failure of a long-term ameliorative strategy to extract meaningful conclusions for further therapeutical design. Although this treatment demonstrated an improvement in the rotarod task performance and aggregate load reduction in the early stage of the pathology, this amelioration was later lost at the same time that the gene induction of HSPs was impaired, as observed by microarray analyses. This impairment was explained on the basis of a reduction in the binding of HSF1 at HSP gene promoters, where histone H4 was found to be hypoacetylated [119]. ChIP-seq analysis in a Drosophila cell line demonstrated that histone acetylation determines the inducible binding of the fly HSF1 ortholog [178]. Therefore, reversing histone acetylation deficits (e.g., by HDACi treatment) may extend the activation of HSPs in the treatment of HD.

\section{REST Inhibitors}

Screening libraries of compounds may identify novel drugs that modulate the activity of deregulated expression regulators in HD. In a structural-based approach, one screen retrieved quinolone-like compound 91, which reduced REST occupancy at the BDNF locus by reducing the activity of the RESTinteracting partner Sin3b [179]. In another screen, several derivatives of benzoimidazole-5-carboxamide and pyrazole propionamide were able to reduce the luciferase activity driven by REST-binding motifs [180]. One of these derivatives (X5050) exerted its action by promoting REST protein degradation without interfering with its DNA binding or transcript levels. Confirmatory microarray analysis of neuronal stem cells treated with X5050 demonstrated a transcriptomic effect in which upregulation was predominantly enriched in neuronal genes predicted to be controlled by REST, with a concomitant downregulation of chromatin-related genes. As a validation of the activity of X5050 in a HD context, the expression of neuronal markers was increased after treatment in a stem cell model of HD and in chemically lesioned striata [180].

\section{Final Remarks}

Aberrant expanded polyQ stretches, independently of the gene context, may affect similar regulatory mechanisms that should be reflected at the gene expression level. Thus, models for other polyQ disorders, such as dentatorubropallidoluysian 
atrophy (DRPLA), spinobulbar muscular atrophy (SBMA) or Kennedy disease, and spinocerebellar ataxia types 1 and 7 (SCA1, SCA7), share altered transcriptional genes with HD signatures [22, 26, 30, 181, 182].

Similarities can be extended to other neurodegenerative disorders that exhibit common characteristic hallmarks, such as channel-mediated cytotoxicity, mitochondrial dysfunction, intracellular trafficking, and deposition of misfolded proteins may influence and be influenced by shared transcriptional and epigenetic regulatory mechanisms. Therefore, it is not surprising that similar ameliorative strategies in HD are also applicable in other neuropathologies. For example, HDACi have been tested in cognitive pathologies, including neurodegenerative disorders and intellectual disabilities: HD, AD, Parkinson's disease (PD), stroke, traumatic brain injury, amyotrophic lateral sclerosis (ALS), Friedrich ataxia, SBMA, DRLA, and Rubinstein-Taybi syndrome [76, 183, 184]. Anthracyclines have been used in ischemia and oxidative stress [185, 186], and induction of HSPs has been tested in neurodegenerative conditions with a notable presence of protein aggregation (AD, PD, ALS, Prion disease, etc.) [187]. Vice versa, useful insight for HD research can be obtained from transcriptomics analysis performed in models for other disorders, such as the effects of BDNF and environmental enrichment in $\mathrm{AD}[167,188]$. Although still very preliminary, meta-analyses of gene profiles from different neurodegenerative models have been conducted to identify common tractable pathways, such as the immune response and insulinrelated pathways and synaptic-related functions [189-191] to put some examples. However, we need to learn more about HD transcriptional dysregulation, and analytical and experimental procedures should be standardized for better comparisons between conditions. For example, a refinement of the gene profiling studies of HD models at the temporal and cellular resolution is necessary. The use of LCM for the isolation of specific subpopulations, such as the cortical neurons of layer 5 [192] and Purkinje neurons [181], and the generation of animal models with highly specific expression patterns of the $\mathrm{mHtt}$ transgene [57], produce cellular-specific HD signatures with improved sensitivity over whole tissues. Techniques such as fluorescent-activated cell sorting (FACS) or translating ribosomal affinity purification (TRAP) can be useful alternatives. In any case, novel technologies, such as next-generation sequencing, are able to unravel unsuspected features (novel RNA species) or complex relationships (as occurs between transcriptional dysregulation and epigenetic marks). Moreover, the compilation and integration of genome-wide data, including transcriptomics, proteomics, epigenomics, and genomic occupancy, will be necessary for the full comprehension of the biological implications of transcriptional dysregulation in HD and to explore the full potential of genome-wide approaches in the design of improved therapeutics.
Acknowledgments I thank Angel Barco, Jose P. Lopez-Atalaya, and Deisy Guiretti for their critical reading of the manuscript and the Spanish Ministry of Economy and Competitiveness for the economic support (Ramón Cajal contract and grant SAF2011-22506).

Open Access This article is distributed under the terms of the Creative Commons Attribution License which permits any use, distribution, and reproduction in any medium, provided the original author(s) and the source are credited.

\section{References}

1. Bates G, Harper P, Jones L, editors (2004) Huntington's disease. 3rd ed: Oxford University Press

2. Shang H, Danek A, Landwehrmeyer B, Burgunder JM (2012) Huntington's disease: new aspects on phenotype and genotype. Parkinsonism Relat Disord 18(Suppl 1):S107-S109

3. Zuccato C, Valenza M, Cattaneo E (2010) Molecular mechanisms and potential therapeutical targets in Huntington's disease. Physiol Rev 90:905-981

4. Augood SJ, Faull RL, Emson PC (1997) Dopamine D1 and D2 receptor gene expression in the striatum in Huntington's disease. Ann Neurol 42:215-221

5. Emson PC, Arregui A, Clement-Jones V, Sandberg BE, Rossor M (1980) Regional distribution of methionine-enkephalin and substance P-like immunoreactivity in normal human brain and in Huntington's disease. Brain Res 199:147-160

6. Young AB, Greenamyre JT, Hollingsworth Z, Albin R, D'Amato C et al (1988) NMDA receptor losses in putamen from patients with Huntington's disease. Science 241:981-983

7. Cha JH, Kosinski CM, Kerner JA, Alsdorf SA, Mangiarini L et al (1998) Altered brain neurotransmitter receptors in transgenic mice expressing a portion of an abnormal human huntington disease gene. Proc Natl Acad Sci U S A 95:6480-6485

8. Schilling G, Savonenko AV, Klevytska A, Morton JL, Tucker SM et al (2004) Nuclear-targeting of mutant huntingtin fragments produces Huntington's disease-like phenotypes in transgenic mice. Hum Mol Genet 13:1599-1610

9. Benn CL, Landles C, Li H, Strand AD, Woodman B et al (2005) Contribution of nuclear and extranuclear polyQ to neurological phenotypes in mouse models of Huntington's disease. Hum Mol Genet 14:3065-3078

10. Harris AS, Denovan-Wright EM, Hamilton LC, Robertson HA (2001) Protein kinase C beta II mRNA levels decrease in the striatum and cortex of transgenic Huntington's disease mice. J Psychiatry Neurosci 26:117-122

11. Hebb AL, Robertson HA, Denovan-Wright EM (2004) Striatal phosphodiesterase mRNA and protein levels are reduced in Huntington's disease transgenic mice prior to the onset of motor symptoms. Neuroscience 123:967-981

12. Kita H, Carmichael J, Swartz J, Muro S, Wyttenbach A et al (2002) Modulation of polyglutamine-induced cell death by genes identified by expression profiling. Hum Mol Genet 11:2279-2287

13. Packer AN, Xing Y, Harper SQ, Jones L, Davidson BL (2008) The bifunctional microRNA miR-9/miR-9* regulates REST and CoREST and is downregulated in Huntington's disease. J Neurosci 28:14341-14346

14. Sinha M, Ghose J, Das E, Bhattarcharyya NP (2010) Altered microRNAs in STHdh(Q111)/Hdh(Q111) cells: miR-146a targets TBP. Biochem Biophys Res Commun 396:742-747

15. Wyttenbach A, Swartz J, Kita H, Thykjaer T, Carmichael J et al (2001) Polyglutamine expansions cause decreased CRE-mediated transcription and early gene expression changes prior to cell death in 
an inducible cell model of Huntington's disease. Hum Mol Genet 10:1829-1845

16. Marti E, Pantano L, Banez-Coronel M, Llorens F, MinonesMoyano E et al (2010) A myriad of miRNA variants in control and Huntington's disease brain regions detected by massively parallel sequencing. Nucleic Acids Res 38:7219-7235

17. Jin J, Cheng Y, Zhang Y, Wood W, Peng Q et al (2012) Interrogation of brain miRNA and mRNA expression profiles reveals a molecular regulatory network that is perturbed by mutant huntingtin. $\mathrm{J}$ Neurochem 123:477-490

18. Lee ST, Chu K, Im WS, Yoon HJ, Im JY et al (2011) Altered microRNA regulation in Huntington's disease models. Exp Neurol 227:172-179

19. Gaughwin PM, Ciesla M, Lahiri N, Tabrizi SJ, Brundin P et al (2011) Hsa-miR-34b is a plasma-stable microRNA that is elevated in pre-manifest Huntington's disease. Hum Mol Genet 20:22252237

20. Ng CW, Yildirim F, Yap YS, Dalin S, Matthews BJ et al (2013) Extensive changes in DNA methylation are associated with expression of mutant huntingtin. Proc Natl Acad Sci U S A 110:2354-2359

21. Vashishtha M, $\mathrm{Ng} \mathrm{CW}$, Yildirim F, Gipson TA, Kratter IH et al (2013) Targeting H3K4 trimethylation in Huntington disease. Proc Natl Acad Sci U S A 110:E3027-E3036

22. Luthi-Carter R, Strand A, Peters NL, Solano SM, Hollingsworth ZR et al (2000) Decreased expression of striatal signaling genes in a mouse model of Huntington's disease. Hum Mol Genet 9:1259-1271

23. Luthi-Carter R, Hanson SA, Strand AD, Bergstrom DA, Chun W et al (2002) Dysregulation of gene expression in the R6/2 model of polyglutamine disease: parallel changes in muscle and brain. Hum Mol Genet 11:1911-1926

24. Luthi-Carter R, Strand AD, Hanson SA, Kooperberg C, Schilling G et al (2002) Polyglutamine and transcription: gene expression changes shared by DRPLA and Huntington's disease mouse models reveal context-independent effects. Hum Mol Genet 11:1927-1937

25. Strand AD, Aragaki AK, Shaw D, Bird T, Holton J et al (2005) Gene expression in Huntington's disease skeletal muscle: a potential biomarker. Hum Mol Genet 14:1863-1876

26. Abou-Sleymane G, Chalmel F, Helmlinger D, Lardenois A, Thibault $C$ et al (2006) Polyglutamine expansion causes neurodegeneration by altering the neuronal differentiation program. Hum Mol Genet 15:691-703

27. Nguyen HP, Metzger S, Holzmann C, Koczan D, Thiesen HJ et al (2008) Age-dependent gene expression profile and protein expression in a transgenic rat model of Huntington's disease. Proteomics: Clin Appl 2:1638-1650

28. Valor LM, Guiretti D, Lopez-Atalaya JP, Barco A (2013) Genomic landscape of transcriptional and epigenetic dysregulation in early onset polyglutamine disease. J Neurosci 33:10471-10482

29. Kocerha J, Liu Y, Willoughby D, Chidamparam K, Benito J et al (2013) Longitudinal transcriptomic dysregulation in the peripheral blood of transgenic Huntington's disease monkeys. BMC Neurosci 14:88

30. Fossale E, Seong IS, Coser KR, Shioda T, Kohane IS et al (2011) Differential effects of the Huntington's disease CAG mutation in striatum and cerebellum are quantitative not qualitative. Hum Mol Genet 20:4258-4267

31. Sipione S, Rigamonti D, Valenza M, Zuccato C, Conti L et al (2002) Early transcriptional profiles in huntingtin-inducible striatal cells by microarray analyses. Hum Mol Genet 11:1953-1965

32. Tagawa K, Marubuchi S, Qi ML, Enokido Y, Tamura T et al (2007) The induction levels of heat shock protein 70 differentiate the vulnerabilities to mutant huntingtin among neuronal subtypes. J Neurosci 27:868-880

33. Runne H, Regulier E, Kuhn A, Zala D, Gokce O et al (2008) Dysregulation of gene expression in primary neuron models of Huntington's disease shows that polyglutamine-related effects on the striatal transcriptome may not be dependent on brain circuitry. $\mathrm{J}$ Neurosci 28:9723-9731

34. Apostol BL, Illes K, Pallos J, Bodai L, Wu J et al (2006) Mutant huntingtin alters MAPK signaling pathways in PC12 and striatal cells: ERK1/2 protects against mutant huntingtin-associated toxicity. Hum Mol Genet 15:273-285

35. Liang Y, Jiang H, Ratovitski T, Jie C, Nakamura M et al (2009) ATF3 plays a protective role against toxicity by $\mathrm{N}$-terminal fragment of mutant huntingtin in stable PC12 cell line. Brain Res 1286: 221-229

36. Hodges A, Strand AD, Aragaki AK, Kuhn A, Sengstag T et al (2006) Regional and cellular gene expression changes in human Huntington's disease brain. Hum Mol Genet 15:965-977

37. Desplats PA, Kass KE, Gilmartin T, Stanwood GD, Woodward EL et al (2006) Selective deficits in the expression of striatal-enriched mRNAs in Huntington's disease. J Neurochem 96:743-757

38. Kuhn A, Goldstein DR, Hodges A, Strand AD, Sengstag T et al (2007) Mutant huntingtin's effects on striatal gene expression in mice recapitulate changes observed in human Huntington's disease brain and do not differ with mutant huntingtin length or wild-type huntingtin dosage. Hum Mol Genet 16:1845-1861

39. Hodges A, Hughes G, Brooks S, Elliston L, Holmans P et al (2008) Brain gene expression correlates with changes in behavior in the R6/1 mouse model of Huntington's disease. Genes Brain Behav 7:288-299

40. Cha JH (2007) Transcriptional signatures in Huntington's disease. Prog Neurobiol 83:228-248

41. Seredenina T, Luthi-Carter R (2012) What have we learned from gene expression profiles in Huntington's disease? Neurobiol Dis 45: $83-98$

42. Gines S, Seong IS, Fossale E, Ivanova E, Trettel F et al (2003) Specific progressive cAMP reduction implicates energy deficit in presymptomatic Huntington's disease knock-in mice. Hum Mol Genet 12:497-508

43. Choi YS, Lee B, Cho HY, Reyes IB, Pu XA et al (2009) CREB is a key regulator of striatal vulnerability in chemical and genetic models of Huntington's disease. Neurobiol Dis 36:259-268

44. DeMarch Z, Giampa C, Patassini S, Bernardi G, Fusco FR (2008) Beneficial effects of rolipram in the R6/2 mouse model of Huntington's disease. Neurobiol Dis 30:375-387

45. Giampa C, Laurenti D, Anzilotti S, Bernardi G, Menniti FS et al (2010) Inhibition of the striatal specific phosphodiesterase PDE10A ameliorates striatal and cortical pathology in R6/2 mouse model of Huntington's disease. PLoS One 5:e13417

46. Valenza M, Cattaneo E (2011) Emerging roles for cholesterol in Huntington's disease. Trends Neurosci 34:474-486

47. Leoni V, Caccia C (2014) Study of cholesterol metabolism in Huntington's disease. Biochem Biophys Res Commun

48. Mangiarini L, Sathasivam K, Seller M, Cozens B, Harper A et al (1996) Exon 1 of the HD gene with an expanded CAG repeat is sufficient to cause a progressive neurological phenotype in transgenic mice. Cell 87:493-506

49. Diamanti D, Mori E, Incarnato D, Malusa F, Fondelli C et al (2013) Whole gene expression profile in blood reveals multiple pathways deregulation in R6/2 mouse model. Biomark Res 1:28

50. Hu Y, Chopra V, Chopra R, Locascio JJ, Liao Z et al (2011) Transcriptional modulator $\mathrm{H} 2 \mathrm{~A}$ histone family, member $\mathrm{Y}$ (H2AFY) marks Huntington disease activity in man and mouse. Proc Natl Acad Sci U S A 108:17141-17146

51. Borovecki F, Lovrecic L, Zhou J, Jeong H, Then F et al (2005) Genome-wide expression profiling of human blood reveals biomarkers for Huntington's disease. Proc Natl Acad Sci U S A 102: 11023-11028

52. Runne H, Kuhn A, Wild EJ, Pratyaksha W, Kristiansen M et al (2007) Analysis of potential transcriptomic biomarkers for Huntington's disease in peripheral blood. Proc Natl Acad Sci U S A 104:14424-14429 
53. Marchina E, Misasi S, Bozzato A, Ferraboli S, Agosti C, et al. (2014) Gene expression profile in fibroblasts of Huntington's disease patients and controls. J Neurol Sci 337:42-46

54. Desplats PA, Denny CA, Kass KE, Gilmartin T, Head SR et al (2007) Glycolipid and ganglioside metabolism imbalances in Huntington's disease. Neurobiol Dis 27:265-277

55. Strand AD, Baquet ZC, Aragaki AK, Holmans P, Yang L et al (2007) Expression profiling of Huntington's disease models suggests that brain-derived neurotrophic factor depletion plays a major role in striatal degeneration. J Neurosci 27:11758-11768

56. Thomas EA, Coppola G, Desplats PA, Tang B, Soragni E et al (2008) The HDAC inhibitor $4 \mathrm{~b}$ ameliorates the disease phenotype and transcriptional abnormalities in Huntington's disease transgenic mice. Proc Natl Acad Sci U S A 105:15564-15569

57. Thomas EA, Coppola G, Tang B, Kuhn A, Kim S et al (2011) In vivo cell-autonomous transcriptional abnormalities revealed in mice expressing mutant huntingtin in striatal but not cortical neurons. Hum Mol Genet 20:1049-1060

58. Calabresi P, Centonze D, Bernardi G (2000) Cellular factors controlling neuronal vulnerability in the brain: a lesson from the striatum. Neurology 55:1249-1255

59. Burke RE, O'Malley K (2013) Axon degeneration in Parkinson's disease. Exp Neurol 246:72-83

60. Tunez I, Tasset I, Perez-De La Cruz V, Santamaria A (2010) 3Nitropropionic acid as a tool to study the mechanisms involved in Huntington's disease: past, present and future. Molecules 15:878-916

61. Telenius H, Kremer B, Goldberg YP, Theilmann J, Andrew SE et al (1994) Somatic and gonadal mosaicism of the Huntington disease gene CAG repeat in brain and sperm. Nat Genet 6:409-414

62. Lee JM, Zhang J, Su AI, Walker JR, Wiltshire T et al (2010) A novel approach to investigate tissue-specific trinucleotide repeat instability. BMC Syst Biol 4:29

63. Mason AG, Tome S, Simard JP, Libby RT, Bammler TK, et al. (2014) Expression levels of DNA replication and repair genes predict regional somatic repeat instability in the brain but are not altered by polyglutamine disease protein expression or age. Hum Mol Genet 23:1606-1618

64. Jeong H, Then F, Melia TJ Jr, Mazzulli JR, Cui L et al (2009) Acetylation targets mutant huntingtin to autophagosomes for degradation. Cell 137:60-72

65. Chan EY, Luthi-Carter R, Strand A, Solano SM, Hanson SA et al (2002) Increased huntingtin protein length reduces the number of polyglutamine-induced gene expression changes in mouse models of Huntington's disease. Hum Mol Genet 11:1939-1951

66. Tang B, Becanovic K, Desplats PA, Spencer B, Hill AM et al (2012) Forkhead box protein $\mathrm{p} 1$ is a transcriptional repressor of immune signaling in the CNS: implications for transcriptional dysregulation in Huntington disease. Hum Mol Genet 21:3097-3111

67. Jacobsen JC, Gregory GC, Woda JM, Thompson MN, Coser KR et al (2011) HD CAG-correlated gene expression changes support a simple dominant gain of function. Hum Mol Genet 20:2846-2860

68. Lee JM, Galkina EI, Levantovsky RM, Fossale E, Anne Anderson $M$ et al (2013) Dominant effects of the Huntington's disease HTT CAG repeat length are captured in gene-expression data sets by a continuous analysis mathematical modeling strategy. Hum Mol Genet 22:3227-3238

69. Kuhn A, Thu D, Waldvogel HJ, Faull RL, Luthi-Carter R (2011) Population-specific expression analysis (PSEA) reveals molecular changes in diseased brain. Nat Methods 8:945-947

70. Lovrecic L, Slavkov I, Dzeroski S, Peterlin B (2010) ADPribosylation factor guanine nucleotide-exchange factor 2 (ARFGEF2): a new potential biomarker in Huntington's disease. J Int Med Res 38:1653-1662

71. Chaturvedi RK, Beal MF (2013) Mitochondria targeted therapeutic approaches in Parkinson's and Huntington's diseases. Mol Cell Neurosci 55:101-114
72. Lee JM, Ivanova EV, Seong IS, Cashorali T, Kohane I et al (2007) Unbiased gene expression analysis implicates the huntingtin polyglutamine tract in extra-mitochondrial energy metabolism. PLoS Genet 3:e135

73. Jakovcevski M, Akbarian S (2012) Epigenetic mechanisms in neurological disease. Nat Med 18:1194-1204

74. Urdinguio RG, Sanchez-Mut JV, Esteller M (2009) Epigenetic mechanisms in neurological diseases: genes, syndromes, and therapies. Lancet Neurol 8:1056-1072

75. Saha RN, Pahan K (2006) HATs and HDACs in neurodegeneration: a tale of disconcerted acetylation homeostasis. Cell Death Differ 13: $539-550$

76. Valor LM, Guiretti D (2014) What's wrong with epigenetics in Huntington's disease? Neuropharmacology 80C:103-114

77. Maciotta S, Meregalli M, Torrente Y (2013) The involvement of microRNAs in neurodegenerative diseases. Front Cell Neurosci 7: 265

78. Stroynowska-Czerwinska A, Fiszer A, Krzyzosiak WJ (2014) The panorama of miRNA-mediated mechanisms in mammalian cells. Cell Mol Life Sci

79. Johnson R, Zuccato C, Belyaev ND, Guest DJ, Cattaneo E et al (2008) A microRNA-based gene dysregulation pathway in Huntington's disease. Neurobiol Dis 29:438-445

80. Banez-Coronel M, Porta S, Kagerbauer B, Mateu-Huertas E, Pantano L et al (2012) A pathogenic mechanism in Huntington's disease involves small CAG-repeated RNAs with neurotoxic activity. PLoS Genet 8:e1002481

81. Zuccato C, Tartari M, Crotti A, Goffredo D, Valenza M et al (2003) Huntingtin interacts with REST/NRSF to modulate the transcription of NRSE-controlled neuronal genes. Nat Genet 35:76-83

82. Marcora E, Kennedy MB (2010) The Huntington's disease mutation impairs Huntingtin's role in the transport of NF-kappaB from the synapse to the nucleus. Hum Mol Genet 19:4373-4384

83. Futter M, Diekmann H, Schoenmakers E, Sadiq O, Chatterjee K et al (2009) Wild-type but not mutant huntingtin modulates the transcriptional activity of liver X receptors. J Med Genet 46:438446

84. Steffan JS, Kazantsev A, Spasic-Boskovic O, Greenwald M, Zhu YZ et al (2000) The Huntington's disease protein interacts with p53 and CREB-binding protein and represses transcription. Proc Natl Acad Sci U S A 97:6763-6768

85. Boutell JM, Thomas P, Neal JW, Weston VJ, Duce J et al (1999) Aberrant interactions of transcriptional repressor proteins with the Huntington's disease gene product, huntingtin. Hum Mol Genet 8: $1647-1655$

86. Kazantsev A, Preisinger E, Dranovsky A, Goldgaber D, Housman D (1999) Insoluble detergent-resistant aggregates form between pathological and nonpathological lengths of polyglutamine in mammalian cells. Proc Natl Acad Sci U S A 96:11404-11409

87. Huang CC, Faber PW, Persichetti F, Mittal V, Vonsattel JP et al (1998) Amyloid formation by mutant huntingtin: threshold, progressivity and recruitment of normal polyglutamine proteins. Somat Cell Mol Genet 24:217-233

88. Holbert S, Denghien I, Kiechle T, Rosenblatt A, Wellington C et al (2001) The Gln-Ala repeat transcriptional activator CA150 interacts with huntingtin: neuropathologic and genetic evidence for a role in Huntington's disease pathogenesis. Proc Natl Acad Sci U S A 98: 1811-1816

89. Valenza M, Rigamonti D, Goffredo D, Zuccato C, Fenu S et al (2005) Dysfunction of the cholesterol biosynthetic pathway in Huntington's disease. J Neurosci 25:9932-9939

90. Obrietan K, Hoyt KR (2004) CRE-mediated transcription is increased in Huntington's disease transgenic mice. J Neurosci 24: 791-796

91. Sugars KL, Brown R, Cook LJ, Swartz J, Rubinsztein DC (2004) Decreased cAMP response element-mediated transcription: an early 
event in exon 1 and full-length cell models of Huntington's disease that contributes to polyglutamine pathogenesis. J Biol Chem 279: 4988-4999

92. Lu B, Palacino J (2013) A novel human embryonic stem cellderived Huntington's disease neuronal model exhibits mutant huntingtin (mHTT) aggregates and soluble mHTT-dependent neurodegeneration. FASEB J 27:1820-1829

93. Leitman J, Ulrich Hartl F, Lederkremer GZ (2013) Soluble forms of polyQ-expanded huntingtin rather than large aggregates cause endoplasmic reticulum stress. Nat Commun 4:2753

94. Tian J, Yan YP, Zhou R, Lou HF, Rong Y, et al. (2013) Soluble Nterminal fragment of mutant Huntingtin protein impairs mitochondrial axonal transport in cultured hippocampal neurons. Neurosci Bull

95. Arrasate M, Finkbeiner S (2012) Protein aggregates in Huntington's disease. Exp Neurol 238:1-11

96. Yu ZX, Li SH, Nguyen HP, Li XJ (2002) Huntingtin inclusions do not deplete polyglutamine-containing transcription factors in HD mice. Hum Mol Genet 11:905-914

97. Tallaksen-Greene SJ, Crouse AB, Hunter JM, Detloff PJ, Albin RL (2005) Neuronal intranuclear inclusions and neuropil aggregates in HdhCAG(150) knockin mice. Neuroscience 131:843-852

98. Cong SY, Pepers BA, Evert BO, Rubinsztein DC, Roos RA et al (2005) Mutant huntingtin represses CBP, but not p300, by binding and protein degradation. Mol Cell Neurosci 30:560-571

99. Choi YJ, Kim SI, Lee JW, Kwon YS, Lee HJ et al (2012) Suppression of aggregate formation of mutant huntingtin potentiates CREB-binding protein sequestration and apoptotic cell death. Mol Cell Neurosci 49:127-137

100. Dunah AW, Jeong H, Griffin A, Kim YM, Standaert DG et al (2002) Sp1 and TAFII130 transcriptional activity disrupted in early Huntington's disease. Science 296:2238-2243

101. Li SH, Cheng AL, Zhou H, Lam S, Rao M et al (2002) Interaction of Huntington disease protein with transcriptional activator Sp1. Mol Cell Biol 22:1277-1287

102. Sadri-Vakili G, Menon AS, Farrell LA, Keller-McGandy CE, Cantuti-Castelvetri I et al (2006) Huntingtin inclusions do not down-regulate specific genes in the R6/2 Huntington's disease mouse. Eur J Neurosci 23:3171-3175

103. Benn CL, Sun T, Sadri-Vakili G, McFarland KN, DiRocco DP et al (2008) Huntingtin modulates transcription, occupies gene promoters in vivo, and binds directly to DNA in a polyglutaminedependent manner. J Neurosci 28:10720-10733

104. Cui L, Jeong H, Borovecki F, Parkhurst CN, Tanese N et al (2006) Transcriptional repression of PGC-1alpha by mutant huntingtin leads to mitochondrial dysfunction and neurodegeneration. Cell 127:59-69

105. Yamanaka T, Miyazaki H, Oyama F, Kurosawa M, Washizu C et al (2008) Mutant Huntingtin reduces HSP70 expression through the sequestration of NF-Y transcription factor. EMBO J 27:827-839

106. Godin JD, Poizat G, Hickey MA, Maschat F, Humbert S (2010) Mutant huntingtin-impaired degradation of beta-catenin causes neurotoxicity in Huntington's disease. EMBO J 29:2433-2445

107. Saura CA, Valero J (2011) The role of CREB signaling in Alzheimer's disease and other cognitive disorders. Rev Neurosci 22:153-169

108. Datta M, Choudhury A, Lahiri A, Bhattacharyya NP (2011) Genome wide gene expression regulation by HIP1 Protein Interactor, HIPPI: prediction and validation. BMC Genomics 12: 463

109. Jovicic A, Zaldivar Jolissaint JF, Moser R, Silva Santos Mde F, Luthi-Carter R (2013) MicroRNA-22 (miR-22) overexpression is neuroprotective via general anti-apoptotic effects and may also target specific Huntington's disease-related mechanisms. PLoS One 8:e54222

110. Zuccato C, Belyaev N, Conforti P, Ooi L, Tartari M et al (2007) Widespread disruption of repressor element-1 silencing transcription factor/neuron-restrictive silencer factor occupancy at its target genes in Huntington's disease. J Neurosci 27:6972-6983

111. McFarland KN, Das S, Sun TT, Leyfer D, Xia E et al (2012) Genome-wide histone acetylation is altered in a transgenic mouse model of Huntington's disease. PLoS One 7:e41423

112. Riva L, Koeva M, Yildirim F, Pirhaji L, Dinesh D et al (2012) Polyglutamine expanded huntingtin dramatically alters the genome wide binding of HSF1. J Huntingtons Dis 1:33-45

113. Lee J, Hwang YJ, Shin JY, Lee WC, Wie J et al (2013) Epigenetic regulation of cholinergic receptor M1 (CHRM1) by histone H3K9me3 impairs $\mathrm{Ca}(2+)$ signaling in Huntington's disease. Acta Neuropathol 125:727-739

114. Adachi M, Monteggia LM (2014) Decoding transcriptional repressor complexes in the adult central nervous system. Neuropharmacology 80C:45-52

115. Johnson R, Richter N, Jauch R, Gaughwin PM, Zuccato C, et al. (2010) The Human Accelerated Region 1 noncoding RNA is repressed by REST in Huntington's disease. Physiol Genomics 41: 269-274

116. Soldati C, Bithell A, Johnston C, Wong KY, Stanton LW et al (2013) Dysregulation of REST-regulated coding and non-coding RNAs in a cellular model of Huntington's disease. J Neurochem 124:418-430

117. Le Fevre AK, Taylor S, Malek NH, Horn D, Carr CW et al (2013) FOXP1 mutations cause intellectual disability and a recognizable phenotype. Am J Med Genet A 161A:3166-3175

118. Hay DG, Sathasivam K, Tobaben S, Stahl B, Marber M et al (2004) Progressive decrease in chaperone protein levels in a mouse model of Huntington's disease and induction of stress proteins as a therapeutic approach. Hum Mol Genet 13:1389-1405

119. Labbadia J, Cunliffe H, Weiss A, Katsyuba E, Sathasivam K et al (2011) Altered chromatin architecture underlies progressive impairment of the heat shock response in mouse models of Huntington disease. J Clin Invest 121:3306-3319

120. Lucas EK, Dougherty SE, McMeekin LJ, Trinh AT, Reid CS et al (2012) Developmental alterations in motor coordination and medium spiny neuron markers in mice lacking pgc-1alpha. PLoS One 7:e42878

121. Levenson JM, O'Riordan KJ, Brown KD, Trinh MA, Molfese DL et al (2004) Regulation of histone acetylation during memory formation in the hippocampus. J Biol Chem 279:40545-40559

122. Peleg S, Sananbenesi F, Zovoilis A, Burkhardt S, Bahari-Javan S et al (2010) Altered histone acetylation is associated with agedependent memory impairment in mice. Science 328:753-756

123. Parkel S, Lopez-Atalaya JP, Barco A (2013) Histone H3 lysine methylation in cognition and intellectual disability disorders. Learn Mem 20:570-579

124. Wang F, Yang Y, Lin X, Wang JQ, Wu YS et al (2013) Genomewide loss of 5-hmC is a novel epigenetic feature of Huntington's disease. Hum Mol Genet 22:3641-3653

125. Giorgini F, Moller T, Kwan W, Zwilling D, Wacker JL et al (2008) Histone deacetylase inhibition modulates kynurenine pathway activation in yeast, microglia, and mice expressing a mutant huntingtin fragment. J Biol Chem 283:7390-7400

126. Kurdistani SK, Robyr D, Tavazoie S, Grunstein M (2002) Genomewide binding map of the histone deacetylase Rpd3 in yeast. Nat Genet 31:248-254

127. Tauber E, Miller-Fleming L, Mason RP, Kwan W, Clapp J et al (2011) Functional gene expression profiling in yeast implicates translational dysfunction in mutant huntingtin toxicity. J Biol Chem 286:410-419

128. Mielcarek M, Landles C, Weiss A, Bradaia A, Seredenina T et al (2013) HDAC4 reduction: a novel therapeutic strategy to target cytoplasmic huntingtin and ameliorate neurodegeneration. PLoS Biol 11:e1001717

129. Sando R 3rd, Gounko N, Pieraut S, Liao L, Yates J 3rd et al (2012) HDAC4 governs a transcriptional program essential for synaptic plasticity and memory. Cell 151:821-834 
130. Mielcarek M, Seredenina T, Stokes MP, Osborne GF, Landles C et al (2013) HDAC4 does not act as a protein deacetylase in the postnatal murine brain in vivo. PLoS One 8:e80849

131. Kegel KB, Meloni AR, Yi Y, Kim YJ, Doyle E et al (2002) Huntingtin is present in the nucleus, interacts with the transcriptional corepressor $\mathrm{C}$-terminal binding protein, and represses transcription. J Biol Chem 277:7466-7476

132. Ferrante RJ, Ryu H, Kubilus JK, D'Mello S, Sugars KL et al (2004) Chemotherapy for the brain: the antitumor antibiotic mithramycin prolongs survival in a mouse model of Huntington's disease. J Neurosci 24:10335-10342

133. Stack EC, Del Signore SJ, Luthi-Carter R, Soh BY, Goldstein DR et al (2007) Modulation of nucleosome dynamics in Huntington's disease. Hum Mol Genet 16:1164-1175

134. Ryu H, Lee J, Hagerty SW, Soh BY, McAlpin SE et al (2006) ESET/SETDB1 gene expression and histone H3 (K9) trimethylation in Huntington's disease. Proc Natl Acad Sci U S A 103:19176-19181

135. Gardian G, Browne SE, Choi DK, Klivenyi P, Gregorio J et al (2005) Neuroprotective effects of phenylbutyrate in the N171-82Q transgenic mouse model of Huntington's disease. J Biol Chem 280: $556-563$

136. Lee J, Hong YK, Jeon GS, Hwang YJ, Kim KY et al (2012) ATRX induction by mutant huntingtin via $\mathrm{Cdx} 2$ modulates heterochromatin condensation and pathology in Huntington's disease. Cell Death Differ 19:1109-1116

137. Lee J, Hagerty S, Cormier KA, Kim J, Kung AL et al (2008) Monoallele deletion of CBP leads to pericentromeric heterochromatin condensation through ESET expression and histone H3 (K9) methylation. Hum Mol Genet 17:1774-1782

138. Buckley NJ, Johnson R, Zuccato C, Bithell A, Cattaneo E (2010) The role of REST in transcriptional and epigenetic dysregulation in Huntington's disease. Neurobiol Dis 39:28-39

139. Soldati C, Bithell A, Conforti P, Cattaneo E, Buckley NJ (2011) Rescue of gene expression by modified REST decoy oligonucleotides in a cellular model of Huntington's disease. J Neurochem 116: $415-425$

140. Stadler MB, Murr R, Burger L, Ivanek R, Lienert F et al (2011) DNA-binding factors shape the mouse methylome at distal regulatory regions. Nature 480:490-495

141. Martin E, Betuing S, Pages C, Cambon K, Auregan G et al (2011) Mitogen- and stress-activated protein kinase 1-induced neuroprotection in Huntington's disease: role on chromatin remodeling at the PGC-1-alpha promoter. Hum Mol Genet 20:2422-2434

142. Bae BI, Xu H, Igarashi S, Fujimuro M, Agrawal N et al (2005) p53 mediates cellular dysfunction and behavioral abnormalities in Huntington's disease. Neuron 47:29-41

143. Jiang M, Wang J, Fu J, Du L, Jeong H et al (2012) Neuroprotective role of Sirt1 in mammalian models of Huntington's disease through activation of multiple Sirt1 targets. Nat Med 18:153-158

144. Illuzzi JL, Vickers CA, Kmiec EB (2011) Modifications of p53 and the DNA damage response in cells expressing mutant form of the protein huntingtin. J Mol Neurosci 45:256-268

145. Brooks CL, Gu W (2011) The impact of acetylation and deacetylation on the $\mathrm{p} 53$ pathway. Protein Cell 2:456-462

146. Brochier C, Dennis G, Rivieccio MA, McLaughlin K, Coppola G et al (2013) Specific acetylation of p53 by HDAC inhibition prevents DNA damage-induced apoptosis in neurons. J Neurosci 33: $8621-8632$

147. Lee J, Hwang YJ, Boo JH, Han D, Kwon OK et al (2011) Dysregulation of upstream binding factor-1 acetylation at K352 is linked to impaired ribosomal DNA transcription in Huntington's disease. Cell Death Differ 18:1726-1735

148. Altar CA, Vawter MP, Ginsberg SD (2009) Target identification for CNS diseases by transcriptional profiling. Neuropsychopharmacology 34:18-54
149. Valor LM, Barco A (2012) Hippocampal gene profiling: toward a systems biology of the hippocampus. Hippocampus 22:929-941

150. Zhang Y, Friedlander RM (2011) Using non-coding small RNAs to develop therapies for Huntington's disease. Gene Ther 18:11391149

151. Drouet V, Perrin V, Hassig R, Dufour N, Auregan G et al (2009) Sustained effects of nonallele-specific Huntingtin silencing. Ann Neurol 65:276-285

152. Boudreau RL, McBride JL, Martins I, Shen S, Xing Y et al (2009) Nonallele-specific silencing of mutant and wild-type huntingtin demonstrates therapeutic efficacy in Huntington's disease mice. Mol Ther 17:1053-1063

153. Grondin R, Kaytor MD, Ai Y, Nelson PT, Thakker DR et al (2012) Six-month partial suppression of Huntingtin is well tolerated in the adult rhesus striatum. Brain 135:1197-1209

154. Strehlow AN, Li JZ, Myers RM (2007) Wild-type huntingtin participates in protein trafficking between the Golgi and the extracellular space. Hum Mol Genet 16:391-409

155. Zhang H, Das S, Li QZ, Dragatsis I, Repa J et al (2008) Elucidating a normal function of huntingtin by functional and microarray analysis of huntingtin-null mouse embryonic fibroblasts. BMC Neurosci 9:38

156. Boudreau RL, Spengler RM, Davidson BL (2011) Rational design of therapeutic siRNAs: minimizing off-targeting potential to improve the safety of RNAi therapy for Huntington's disease. Mol Ther 19:2169-2177

157. Yamamoto A, Cremona ML, Rothman JE (2006) Autophagymediated clearance of huntingtin aggregates triggered by the insulin-signaling pathway. J Cell Biol 172:719-731

158. Varma H, Yamamoto A, Sarantos MR, Hughes RE, Stockwell BR (2010) Mutant huntingtin alters cell fate in response to microtubule depolymerization via the GEF-H1-RhoA-ERK pathway. J Biol Chem 285:37445-37457

159. Morton AJ, Hunt MJ, Hodges AK, Lewis PD, Redfern AJ et al (2005) A combination drug therapy improves cognition and reverses gene expression changes in a mouse model of Huntington's disease. Eur J Neurosci 21:855-870

160. Hockly E, Cordery PM, Woodman B, Mahal A, van Dellen A et al (2002) Environmental enrichment slows disease progression in R6/ 2 Huntington's disease mice. Ann Neurol 51:235-242

161. Spires TL, Grote HE, Varshney NK, Cordery PM, van Dellen A et al (2004) Environmental enrichment rescues protein deficits in a mouse model of Huntington's disease, indicating a possible disease mechanism. J Neurosci 24:2270-2276

162. Nithianantharajah J, Barkus C, Murphy M, Hannan AJ (2008) Gene-environment interactions modulating cognitive function and molecular correlates of synaptic plasticity in Huntington's disease transgenic mice. Neurobiol Dis 29:490-504

163. van Dellen A, Blakemore C, Deacon R, York D, Hannan AJ (2000) Delaying the onset of Huntington's in mice. Nature 404:721-722

164. Nithianantharajah J, Hannan AJ (2006) Enriched environments, experience-dependent plasticity and disorders of the nervous system. Nat Rev Neurosci 7:697-709

165. Benn CL, Luthi-Carter R, Kuhn A, Sadri-Vakili G, Blankson KL et al (2010) Environmental enrichment reduces neuronal intranuclear inclusion load but has no effect on messenger RNA expression in a mouse model of Huntington disease. J Neuropathol Exp Neurol 69:817-827

166. Rampon C, Jiang CH, Dong H, Tang YP, Lockhart DJ et al (2000) Effects of environmental enrichment on gene expression in the brain. Proc Natl Acad Sci U S A 97:12880-12884

167. Lazarov O, Robinson J, Tang YP, Hairston IS, Korade-Mirnics Z et al (2005) Environmental enrichment reduces Abeta levels and amyloid deposition in transgenic mice. Cell 120:701-713

168. Lopez-Atalaya JP, Ciccarelli A, Viosca J, Valor LM, JimenezMinchan $M$ et al (2011) CBP is required for environmental 
enrichment-induced neurogenesis and cognitive enhancement. EMBO J 30:4287-4298

169. Cattaneo E, Zuccato C, Tartari M (2005) Normal huntingtin function: an alternative approach to Huntington's disease. Nat Rev Neurosci 6:919-930

170. Xie Y, Hayden MR, Xu B (2010) BDNF overexpression in the forebrain rescues Huntington's disease phenotypes in YAC128 mice. J Neurosci 30:14708-14718

171. Giampa C, Montagna E, Dato C, Melone MA, Bernardi G et al (2013) Systemic delivery of recombinant brain derived neurotrophic factor (BDNF) in the R6/2 mouse model of Huntington's disease. PLoS One 8:e64037

172. Mugat B, Parmentier ML, Bonneaud N, Chan HY, Maschat F (2008) Protective role of Engrailed in a Drosophila model of Huntington's disease. Hum Mol Genet 17:3601-3616

173. Ferrante RJ, Kubilus JK, Lee J, Ryu H, Beesen A et al (2003) Histone deacetylase inhibition by sodium butyrate chemotherapy ameliorates the neurodegenerative phenotype in Huntington's disease mice. J Neurosci 23:9418-9427

174. Luthi-Carter R, Taylor DM, Pallos J, Lambert E, Amore A et al (2010) SIRT2 inhibition achieves neuroprotection by decreasing sterol biosynthesis. Proc Natl Acad Sci U S A 107:7927-7932

175. Choudhary C, Kumar C, Gnad F, Nielsen ML, Rehman M et al (2009) Lysine acetylation targets protein complexes and coregulates major cellular functions. Science 325:834-840

176. Pang B, Qiao X, Janssen L, Velds A, Groothuis T et al (2013) Druginduced histone eviction from open chromatin contributes to the chemotherapeutic effects of doxorubicin. Nat Commun 4:1908

177. Nagai Y, Fujikake N, Popiel HA, Wada K (2010) Induction of molecular chaperones as a therapeutic strategy for the polyglutamine diseases. Curr Pharm Biotechnol 11:188-197

178. Guertin MJ, Petesch SJ, Zobeck KL, Min IM, Lis JT (2010) Drosophila heat shock system as a general model to investigate transcriptional regulation. Cold Spring Harb Symp Quant Biol 75:1-9

179. Conforti P, Zuccato C, Gaudenzi G, Ieraci A, Camnasio S et al (2013) Binding of the repressor complex REST-mSIN3b by small molecules restores neuronal gene transcription in Huntington's disease models. J Neurochem 127:22-35

180. Charbord J, Poydenot P, Bonnefond C, Feyeux M, Casagrande F et al (2013) High throughput screening for inhibitors of REST in neural derivatives of human embryonic stem cells reveals a chemical compound that promotes expression of neuronal genes. Stem Cells 31:1816-1828

181. Friedrich B, Euler P, Ziegler R, Kuhn A, Landwehrmeyer BG et al (2012) Comparative analyses of Purkinje cell gene expression profiles reveal shared molecular abnormalities in models of different polyglutamine diseases. Brain Res 1481:37-48

182. Euler P, Friedrich B, Ziegler R, Kuhn A, Lindenberg KS et al (2012) Gene expression analysis on a single cell level in Purkinje cells of Huntington's disease transgenic mice. Neurosci Lett 517:7-12

183. Fischer A, Sananbenesi F, Mungenast A, Tsai LH (2010) Targeting the correct HDAC(s) to treat cognitive disorders. Trends Pharmacol Sci 31:605-617

184. Valor LM, Viosca J, Lopez-Atalaya JP, Barco A (2013) Lysine acetyltransferases CBP and p300 as therapeutic targets in cognitive and neurodegenerative disorders. Curr Pharm Des 19:5051-5064

185. Osada N, Kosuge Y, Oguchi S, Miyagishi H, Ishige K et al (2012) Protective action of mithramycin against neurodegeneration and impairment of synaptic plasticity in the hippocampal CA1 area after transient global ischemia. Neurochem Int 60:47-54
186. Sleiman SF, Langley BC, Basso M, Berlin J, Xia L et al (2011) Mithramycin is a gene-selective Sp1 inhibitor that identifies a biological intersection between cancer and neurodegeneration. $\mathrm{J}$ Neurosci 31:6858-6870

187. Paul S, Mahanta S (2014) Association of heat-shock proteins in various neurodegenerative disorders: is it a master key to open the therapeutic door? Mol Cell Biochem 386:45-61

188. Nagahara AH, Merrill DA, Coppola G, Tsukada S, Schroeder BE et al (2009) Neuroprotective effects of brain-derived neurotrophic factor in rodent and primate models of Alzheimer's disease. Nat Med 15:331-337

189. Valor LM, Jancic D, Lujan R, Barco A (2010) Ultrastructural and transcriptional profiling of neuropathological misregulation of CREB function. Cell Death Differ 17:1636-1644

190. Borjabad A, Volsky DJ (2012) Common transcriptional signatures in brain tissue from patients with HIV-associated neurocognitive disorders, Alzheimer's disease, and Multiple Sclerosis. J Neuroimmune Pharmacol 7:914-926

191. Poirel CL, Rahman A, Rodrigues RR, Krishnan A, Addesa JR et al (2013) Reconciling differential gene expression data with molecular interaction networks. Bioinformatics 29:622-629

192. Zucker B, Kama JA, Kuhn A, Thu D, Orlando LR et al (2010) Decreased Lin $7 b$ expression in layer 5 pyramidal neurons may contribute to impaired corticostriatal connectivity in huntington disease. J Neuropathol Exp Neurol 69:880-895

193. Luthi-Carter R, Apostol BL, Dunah AW, DeJohn MM, Farrell LA et al (2003) Complex alteration of NMDA receptors in transgenic Huntington's disease mouse brain: analysis of mRNA and protein expression, plasma membrane association, interacting proteins, and phosphorylation. Neurobiol Dis 14:624-636

194. Kotliarova S, Jana NR, Sakamoto N, Kurosawa M, Miyazaki $\mathrm{H}$ et al (2005) Decreased expression of hypothalamic neuropeptides in Huntington disease transgenic mice with expanded polyglutamine-EGFP fluorescent aggregates. J Neurochem 93:641-653

195. Crocker SF, Costain WJ, Robertson HA (2006) DNA microarray analysis of striatal gene expression in symptomatic transgenic Huntington's mice (R6/2) reveals neuroinflammation and insulin associations. Brain Res 1088:176-186

196. Sadri-Vakili G, Bouzou B, Benn CL, Kim MO, Chawla P et al (2007) Histones associated with downregulated genes are hypoacetylated in Huntington's disease models. Hum Mol Genet 16: 1293-1306

197. Lorincz MT, Zawistowski VA (2009) Expanded CAG repeats in the murine Huntington's disease gene increases neuronal differentiation of embryonic and neural stem cells. Mol Cell Neurosci 40:1-13

198. Tang B, Seredenina T, Coppola G, Kuhn A, Geschwind DH et al (2011) Gene expression profiling of R6/2 transgenic mice with different $\mathrm{CAG}$ repeat lengths reveals genes associated with disease onset and progression in Huntington's disease. Neurobiol Dis 42: 459-467

199. Feyeux M, Bourgois-Rocha F, Redfern A, Giles P, Lefort N et al (2012) Early transcriptional changes linked to naturally occurring Huntington's disease mutations in neural derivatives of human embryonic stem cells. Hum Mol Genet 21:3883-3895

200. Ribeiro FM, Devries RA, Hamilton A, Guimaraes IM, Cregan SP, et al. (2014) Metabotropic glutamate receptor 5 knockout promotes motor and biochemical alterations in a mouse model of Huntington's disease. Hum Mol Genet 23:2030-2042 